\title{
Rapid Manufacturing and Rapid Tooling with Layer Manufacturing (LM) Technologies, State of the Art and Future Perspectives
}

\author{
(Paper initially published in the Annals of the CIRP@, Vol. 52/2/2003) \\ Gideon N. Levy ${ }^{1}$, Ralf Schindel $^{1}$, J.P. Kruth ${ }^{2}$ \\ ${ }^{1}$ FHS University of Applied Sciences St. Gallen, Switzerland \\ ${ }^{2}$ K.U.Leuven, Catholic University Leuven, Belgium
}

\begin{abstract}
Additive processes, which generate parts in a layered way, have more than 15 years of history. These processes are not exclusively used for prototyping any longer. New opportunities and applications in appropriate manufacturing tasks open up, even though the economical impact is still modest.

This review starts with the definition of Rapid Manufacturing and Rapid Tooling, dealing only with direct fabrication methods of components. A systematic material dependent classification of layer manufacturing and process oriented metal part manufacturing techniques are proposed. The generic and the major specific process characteristics and materials are described, mainly for metallic parts, polymer parts and tooling. Examples and applications are cited.

The paper attempts to understand the state of the art and the prospective, to put questions, to understand limits, to show opportunities and to draw conclusions based on the state of the art.
\end{abstract}

\section{Keywords}

Rapid, Manufacturing, Tooling

\section{INTRODUCTION}

Additive processes, which generate parts in a layered way, have 15 years of history (CIRP keynote 1991) [56]. It started in the late 80 's with Stereolithography. Since then, many new ideas have come up, many patents have been deposited, new processes were invented and commercialised, some of which have already disappeared. An overview is given in Table 1.

\begin{tabular}{|l|c|c|}
\hline \multicolumn{1}{|c|}{ Name } & Acronym & $\begin{array}{c}\text { Development } \\
\text { years }\end{array}$ \\
\hline Stereolithography & SLA & $1986-1988$ \\
\hline $\begin{array}{l}\text { Solid Ground Curing } \\
(\dagger=\text { year of } \\
\text { disappearance) }\end{array}$ & SGC & $\begin{array}{c}1986-1988 \\
1999 \dagger\end{array}$ \\
\hline $\begin{array}{l}\text { Laminated Object } \\
\text { Manufacturing }\end{array}$ & LOM & $1985-1991$ \\
\hline $\begin{array}{l}\text { Fused Deposition } \\
\text { Modelling }\end{array}$ & FDM & $1988-1991$ \\
\hline $\begin{array}{l}\text { Selective Laser } \\
\text { Sintering }\end{array}$ & SLS & $1987-1992$ \\
\hline $\begin{array}{l}\text { 3D Printing (Drop on } \\
\text { Bed) }\end{array}$ & 3DP & $1985-1997$ \\
\hline
\end{tabular}

Table 1. LM technologies, acronyms and development years [12].

LM (Layer Manufacturing) technologies are also often referred to as RP (Rapid Prototyping) technologies. A universally agreed terminology does not exist at this point. Some inconsistencies and doubts can be overcome by using the SME published dictionary [94].

It is well known that the introduction of a new manufacturing technology often begins in the field between scientific push and industrial pull. These acceptances evolve usually within a period of 6-10 years and last a further 5-8 years in anticipation of entering in production. After a pioneering and pure research ("PhD") stage we experience an oversell, a disillusion and finally an acceptance: see Figure 1 [128]. This was confirmed at the introduction of EDM, W-EDM, HSC and Laser Cutting. Water Jet Cutting (WJC) is now in its acceptance phase. In the case of LM processes the need is clearly confirmed by the market! We are in the disillusionment stage.

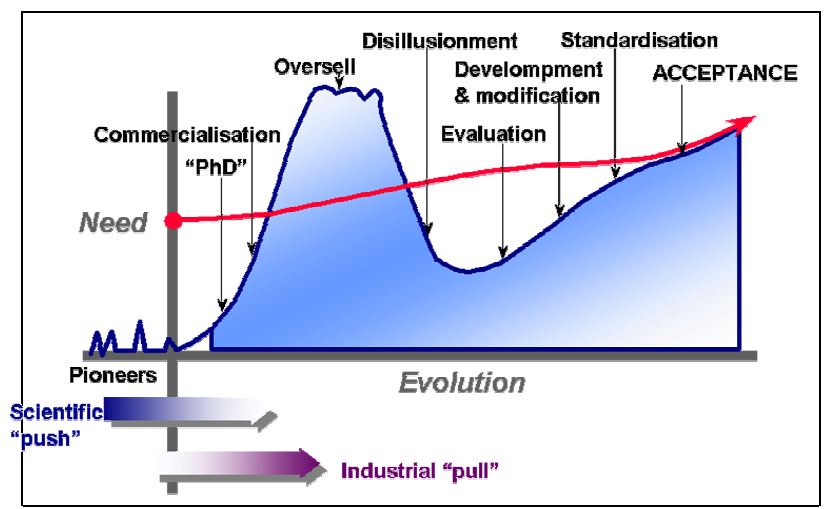

Figure 1. The scientific push and industrial pull in technological evolution.

The situation is also confirmed by the revenue development in this segment (Figure 2) and is presented yearly by Wohlers Association inc. in the book "The state of the Industry" [130].

We are still far below the one billion $\$$ sales. The market volume is steadily increasing but the systems sales show stagnation (Figure 2). This is raising the question of significance and future relevance. Will a significant breakthrough occur? 
Compared to machine tool revenues in other manufacturing sectors the question is even more evident. Take e.g. the EDM market (equipment only) with 1,5-2 billion $\$$ yearly, it is $5-8$ times the RP equipment sales value.

"Time to Market" was originally the strongest inspiration and economical driving force in RP. Product life cycle becomes shorter and builds up interest [68]. Virtual modelling largely fulfils these needs and is in continuous rivalry with RP. This conflict on the other hand increases the interest and chances of RP processes as alternative or autonomous manufacturing processes and augments the interest. The production of long-term usable components and tooling increases the interest in Layer Manufacturing.

The following will attempt to understand the state of the art and the prospective, to put questions, to understand limits, to show chances and to draw conclusions based on the state of the art.

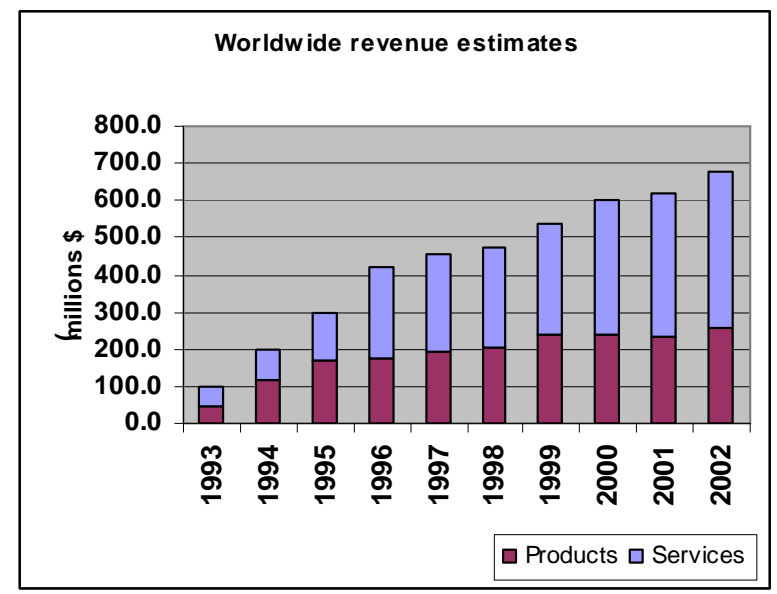

Figure 2. Development of Revenue of RP equipment sales (clear) and services (clear). Source: Wohlers Associates Inc.

\section{DEFINITION AND CLASSIFICATION OF RAPID MANUFACTURING}

The major players in this field have already come to the conclusion that a breakthrough can only happen on the basis of manufacturing applying the RP technologies on a large scale. New terms were created or considered: terms like mass customisation (MC) by Siemens and Phonak [80], Production on Demand (POD) by Boeing, and recently Advanced Digital Manufacturing (AMD) by 3D Systems.

\section{What is Rapid Manufacturing (RM)?}

Rudgley M. defines RM as "the manufacture of enduse products using additive manufacturing techniques (solid imaging)" [106]. RM must guarantee long-term consistent component use for the entire product life cycle or for a defined minimal period for wearing parts. This calls for a most significant role of materials in the LM technologies as argued later.

For long-term consistency, the parts or tools can be made out of four main basic material families fulfilling the required physical, mechanical and geometrical properties (Figure 3). In our definition we consider only direct component production, meaning that the final component is generated directly from a geometry file, at least in a near net shape quality. The indirect production via patterns and reproduction, by e.g. casting, are not considered as LM, even though generative processes have a significant ability and importance representing an important option in those process chains.

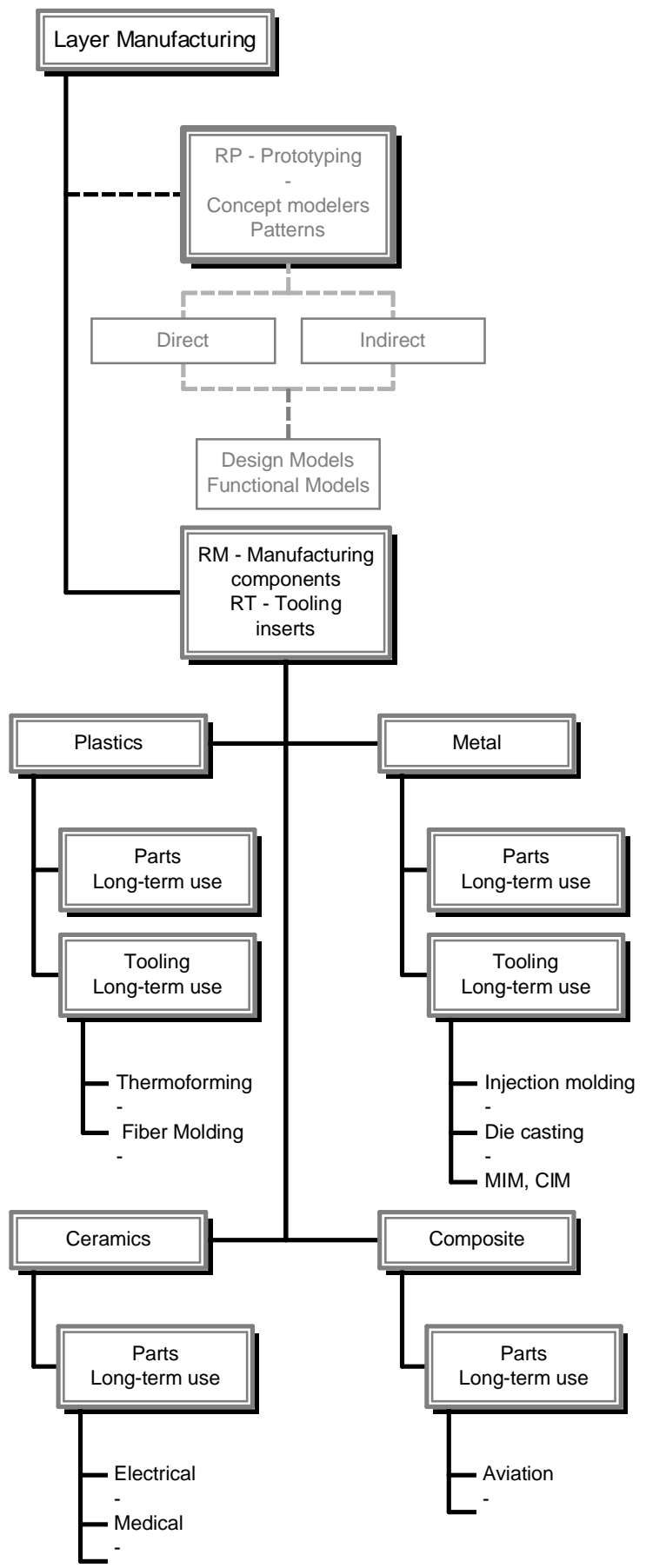

Figure 3. Material dependent Layer Manufacturing - LM structure.

Further, we exclude the Rapid Prototyping issue. It seems that the same processes have found their well defined and justified position in the Rapid Product Development cycle [69] as confirmed by 
Bernard A. and Fischer A. [13] and Levy G. [73] for instance.

\section{DEFINITION AND CLASSIFICATION OF RAPID TOOLING}

Today a great demand exists on RPT-technologies to support product development by tooling or tooling inserts that allow the production of larger series and at the same time enables the production of those parts in materials and with technologies similar to the ones used later for series production runs. The most notable advantage is the integration of production planning and testing within the product development period [38].

\section{What is Rapid Tooling (RT)?}

In contrast to the previous definition of Rapid Manufacturing (RM), Rapid Tooling (RT) aims only at long-term consistency tools, meaning a tool able to form several thousands or even millions of parts before final wearing-out.

Referring to tooling, mainly plastic injection moulds are considered, as these are the most frequently used forming tools. Naturally we have to consider as well other needs with greater difficulty as in die casting, sheet metal forming and forging dies [6] [9] [86] [87] [89]. Those applications increase substantially the requirements on thermal and mechanical load and wear. On the other hand we have also to consider tooling with lower load that is also of great interest: for example for thermoforming, fibre forming and similar processes [29] [77].

So, development and research was initiated for a wide variety of processes [24] [61] [70] [71] [75] [97]. They may be grouped in four categories: Direct and Indirect (indirect means using a part model) procedures and according to the material type in metal or polymer materials [23]. Table 2 gives some examples of such processes.

\begin{tabular}{|l|l|l|}
\hline Material & \multicolumn{1}{|c|}{$\begin{array}{c}\text { Direct } \\
\text { technologies }\end{array}$} & \multicolumn{1}{|c|}{$\begin{array}{c}\text { Indirect } \\
\text { technologies }\end{array}$} \\
\hline \multirow{5}{*}{ Polymer } & Bridge Tooling, & Silicon rubber \\
& CuPA-SLS (3D- & pattern \\
& STstems) & RTV \\
& Swift TM Tooling \\
& SLSLA soft \\
shells & SWIFTTM Tech.) \\
\hline \multirow{5}{*}{ Metal } & DMLSTM (EOS) & KelToolTM (3D- \\
& Rapid Steel 2 & Systems) \\
& LaserForm (3D- & Cast tools \\
& Systems) & Metal spraying \\
& 3D Printing & (HEK) \\
& (ProMetalTM) & Metal deposition \\
\hline
\end{tabular}

Table 2. Process chains options for mould manufacturing.

The rapid tooling options have to be selected in accordance with the final component material and the requested quantity: see Figure 4 . We see clearly that for technically upper end plastics and higher quantities a more sophisticated tooling option has to be selected [123].

A recent DELPHI forecast on Rapid Tooling (RT) use indicated that the well-established quality hardened alloy steel tools are preferred: Figure 5
In the following, we will consider only the direct methods and applications having chances to fulfil a serial production demand in terms of quantity and quality.

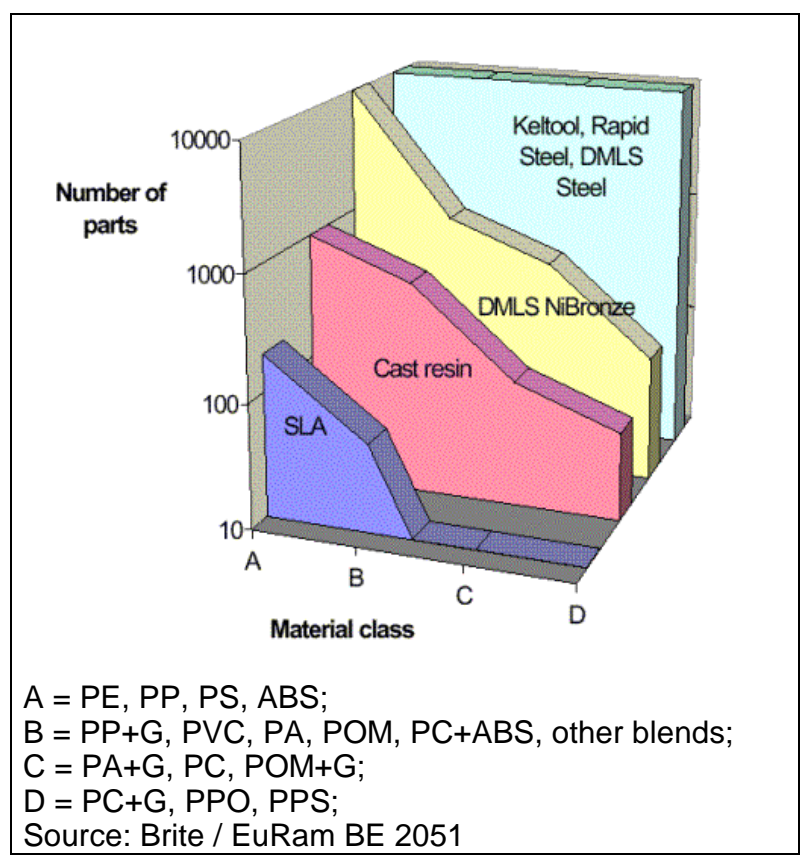

Figure 4. Relations between cast material quantity of parts and selected RT technique.

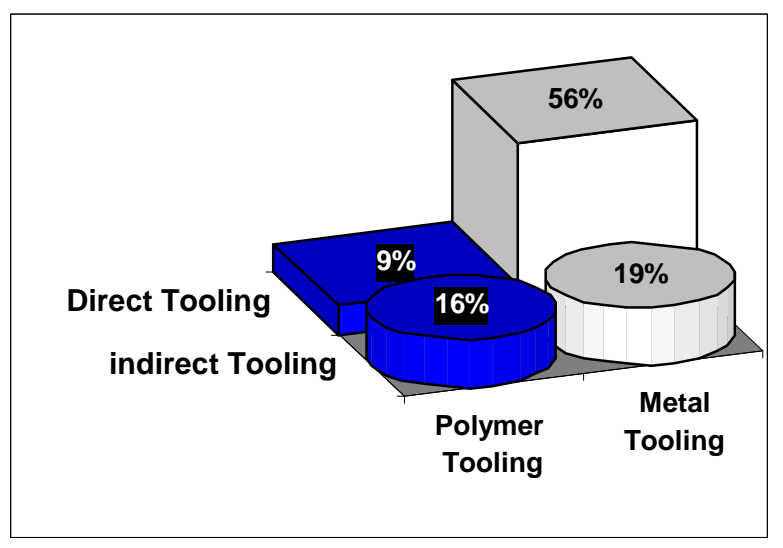

Figure 5. Rapid Tooling classification and users preferences (Source FHS).

\section{THE TECHNOLOGIES INVOLVED}

Over the last decade over 30 companies developed and marketed LM machines based on different physical principles and implementation concepts (see Table 1). All have in common that the components are generated layer by layer also known as "Material Increase Manufacturing" [56]. In general they use the same virtual digital data base, i.e. a volume 3D CAD model in one of the commonly used data formats (STL, DXF, IGES, STEP, etc.). Advanced approaches are investigated [25] [55].

The technologies can be divided as Laser and Nonlaser supported and structured according to the starting material physical state, under the characteristic of RP technologies [56]. 
5 THE MULTIDIMENSIONAL PROPERTIES, AN OBSTACLE OR AN OPPORTUNITY?

All LM technologies have some generic and exclusive common features, which convey a number of synergies among them. The main appeal is towards the novel possibilities and applications offered by those technologies. However, those technologies still differ greatly in terms of physical process, geometry and materials that can be processed and performance (production speed, product strength for given material, etc.). Some decision making methodologies were developed to select the proper process for a particular application or part [79]. Before looking into the single RPprocesses one by one, we will first review the generic issues of geometry, performance and material.

\subsection{Geometry}

The geometrical independence and greater liberty seems to be the most attractive feature of RP processes: undercuts, overhangs, free forms, as well as elementary shapes can be easily produced (Figure 6). This high flexibility opens the way to both small lot and in particular mass customisation. The size of the object is process dependent: SLS, SLA and FDM are typically used for medium size whereas very large parts are limited because of performance and economical considerations besides the availability of commercially large equipment. Today, LM of metallic parts by SLS or laser cladding is typically limited to sizes of $200 \ldots 300 \mathrm{~mm}$. 3D printing has a build size $1000 \times 500 \times 250 \mathrm{~mm}$ and big metal parts were successfully produced. SLS of polymer and sand powders is possible on machines with ranges of $700 \ldots 800 \mathrm{~mm}$. SLA prototypes made from photo-polymer can be built in one piece on machines with a range up to $2200 \mathrm{~mm}$. On the other end of this dimensional-scale LM processes give a chance for complex mini and micro parts [14] [81].

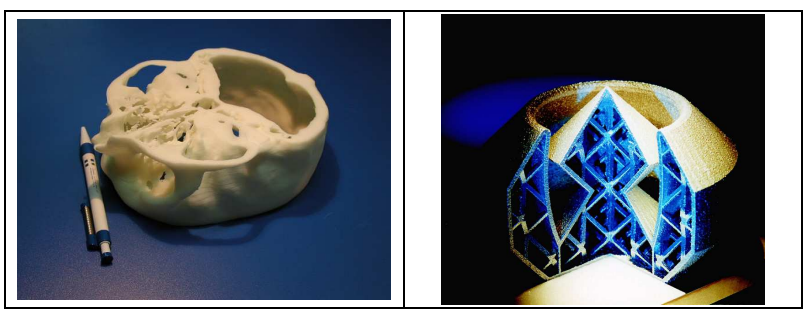

Figure 6. LM complex geometry demonstrated by a medical SLS model made in PA 12 material (left) and a SLM made lightweight part in stainless steel (right) (Source: FHS-RPD, ILT).

The combination of geometrical freedom and mass customisation give an excellent prospect for medical applications (teeth, bones, supports, implants etc.). However the geometrical freedom of some processes is still somewhat restricted by the need to provide and remove support structures underneath the part and within internal cavities or difficulties to remove un-solidified material contained in such part cavities. Some partial solutions to the problem of support structures have been previously reported in a CIRP Keynote 1998 [59].
The almost total liberty in geometrical parts manufacturing opens an interesting application slot between EDM and HSC. The problem of machining deep narrow slots in polymer injection tool inserts can be solved economically as shown in Figure 7. The insert was produced in SLS with integrated conformal cooling and cut with WEDM. Previously sinking-EDM machining of the insert required $2 \times 13$ electrodes. A significant time and cost saving was demonstrated. The tooling process chain can be considerably shortened [109].

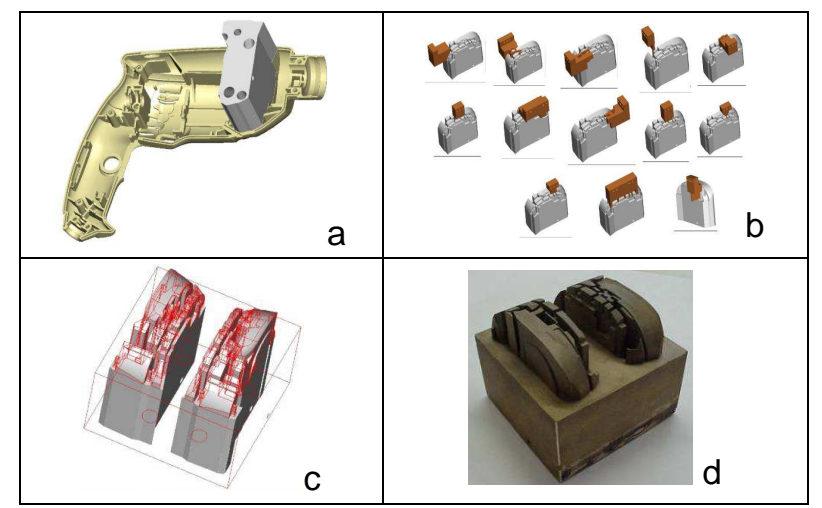

Figure 7. a) Polymer cover with insert, b) EDM required electrodes (13x 2). c) STL data with cooling, d) SLS sintered inserts(Source: FHS-RPD, BOSCH).

The new possibilities may be enhanced with a modified design paradigm "Design for Layer Manufacturing" (DLM). The first steps in this direction are e.g. the design tools for conformal cooling channels [33].

\subsection{RP Process Performance}

All processes still have wide deficiencies with respect to accuracy and repeatability which are typically in the range of 0.1 to $0.2 \mathrm{~mm}$ for $100 \mathrm{~mm}$. A combination with subsequent traditional machining operations for particular features has to be included (at least for the time being) [45] [76].

The surface finish depends on the layer thickness and varies according to the surface inclination; the orientation in the workspace can also influence the functionality of certain surfaces. A characterization for LM parts is proposed by Lonardo P.M. et al [78] and Campbell [18].

Another issue is the productivity [100]. Immense steps forward were implemented in recent years, as for example the scanning speed of SLS started with $1.5 \mathrm{~m} / \mathrm{min}$ in 1996 and recently reached $10 \mathrm{~m} / \mathrm{min}$ with better or equally reliable overall quality. This means a 5 times increase in productivity (Figure 8). An alternative solution is provided by the implemented multi laser beam systems (Figure 9). 


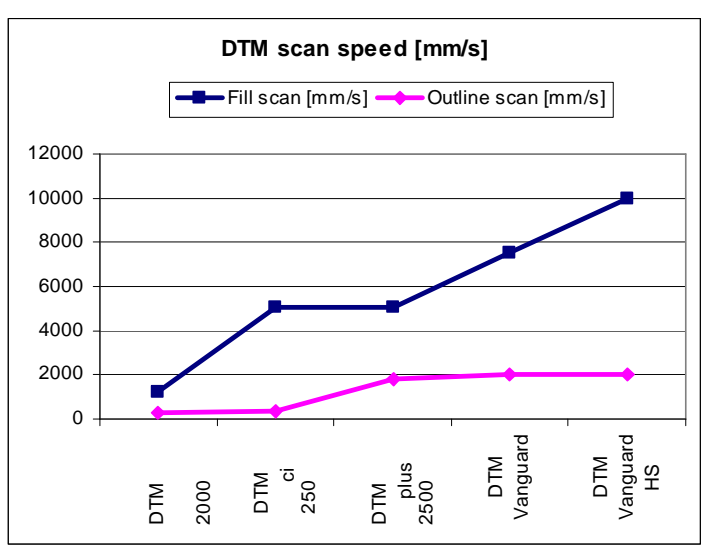

Figure 8. Productivity increase due to laser scan speed.
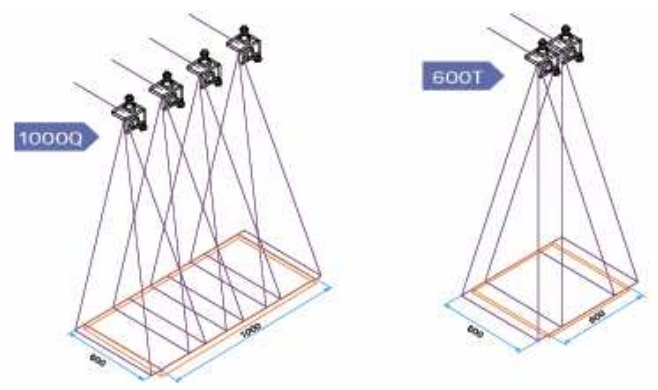

Figure 9. multi beam systems (Source:, $A A A^{+}$ CMET).

\subsection{Material}

The largest difference between LM processes concerns processable materials. The strong link and the extremely small choice of material towards each process is a major constraint (CIRP Keynote 1998) [59].

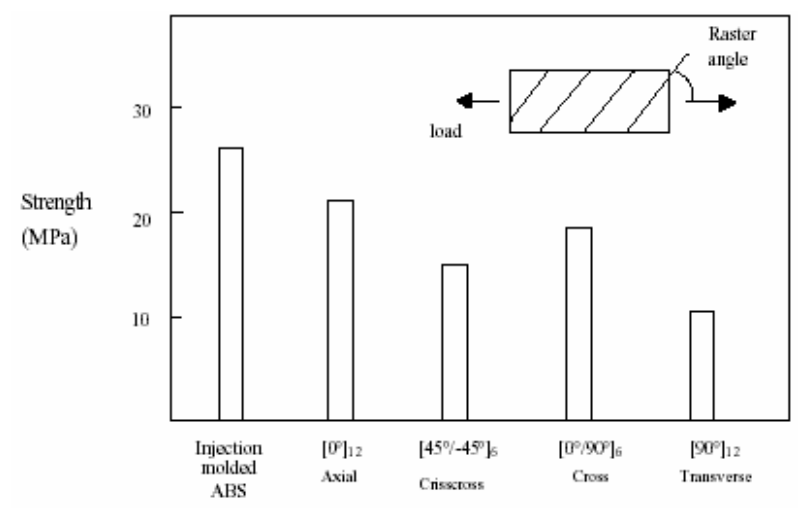

Figure 10. Strength of FDM specimens with various raster orientations (and $0.003 \mathrm{~mm}$ air gaps) compared with injection moulded ABS P300 (Source: Montero).

The selection of a production process becomes unavoidably a design decision and a constructive design complication [110]. A supplementary matter is the anisotropy of the components according to layer orientation. The variance in the mechanical properties has to be considered. A characteristic illustration to validate FDM ABS material is shown in Figure 10. Montero et. al. used DoE (Designed Experiments) for the ABS P400 material characterisation. They demonstrate the strong anisotropy behaviour of the parts and propose designer rules applicable only for simple parts [88]. Typical anisotropy values in several layer directions, for SLS PA12 material is given in [80].

\section{DIRECT MANUFACTURING OF METAL PARTS}

Today, the biggest chances and efforts are placed in the direct manufacture of long-term consistent metal parts [10]. The options are numerous. We can divide the options into two main categories: Non-Melting and Melting processes.

A further substructure reflects the used material form: powder, foils or wire (Figure 11). At the third level we can distinguish between the applied fundamental RP process.

Four basic material forms and 7 different RP principles are competing in direct metal parts fabrication. This requires an accurate validation and trade off for specific applications. However not all processes are equally advanced. Some are only in the very early stages. 18 systems commercially available are listed in Appendix 1.

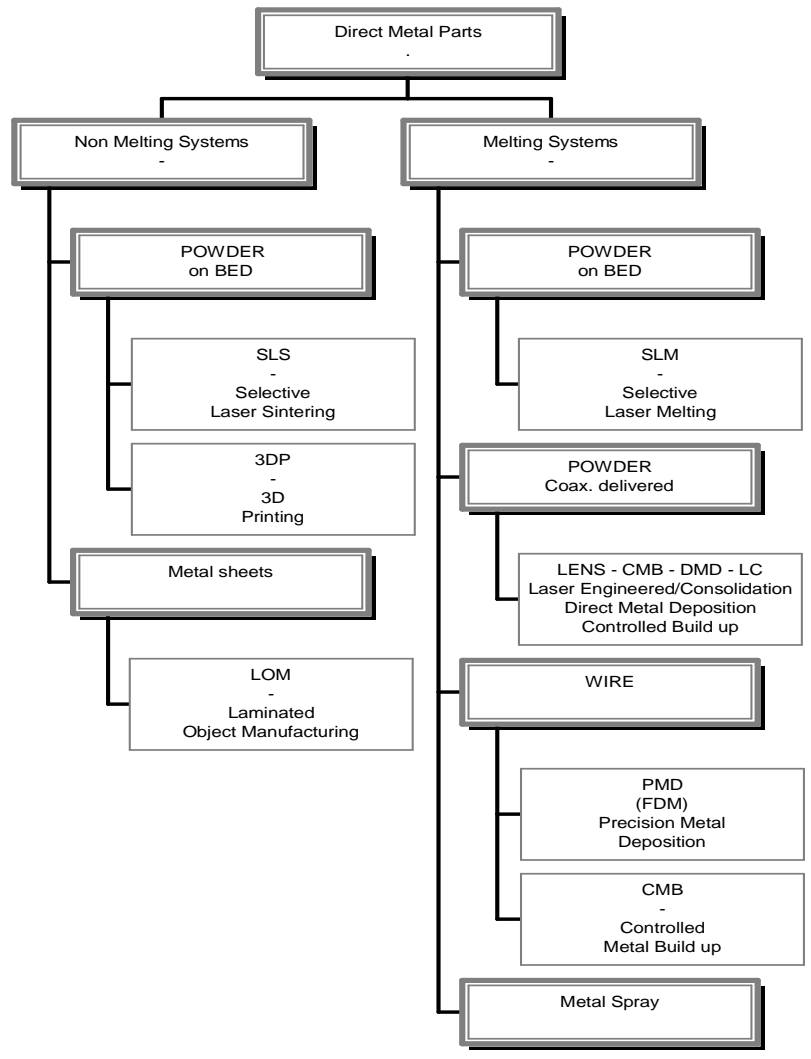

Figure 11. Four basic material forms and seven different RP principles are competing in the direct metal parts fabrication.(see also App. 1).

The competitive position of LM for metal components relative to alternative manufacturing processes is a function of the geometrical complexity and required quantity. A graphical presentation can be extrapolated from the diagram published in reference [85]: Figure 12. LM is positioned at medium to high geometrically complex parts and at relatively low quantities. The borders are floating and have to be evaluated from case to 
case. However, in principle, more productive and better performing LM processes will shift the corresponding upper quantity limit upwards.

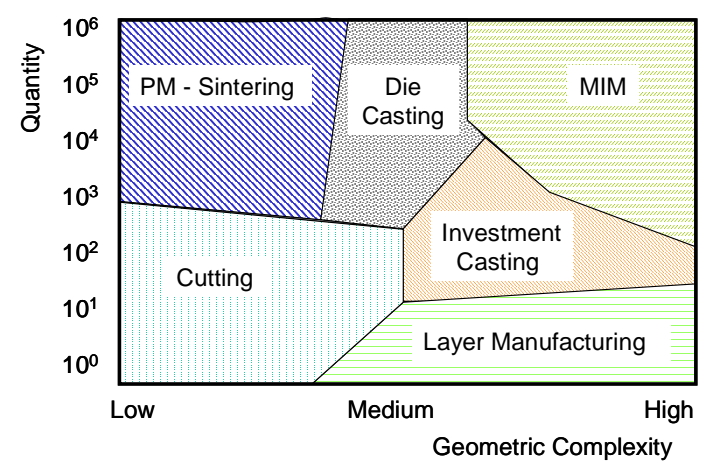

Figure 12. Qualitative situation of the LM direct metal components production relative to usual options.

\subsection{Non Melting LM Processes}

\section{Selective Laser Sintering - SLS}

The selective laser sintering process was first described in the US patent 4247508 by Housholder and was evolved by Deckard at the University of Texas (US 4863538). It became the most advanced process used in Rapid Manufacturing for metallic and polymer parts. The research efforts are very broad in many universities and institutions worldwide.

\begin{tabular}{|c|c|c|c|c|}
\hline Process & SLS & SLS & 3DP & SLM \\
\hline & I stage: & II stages: & III stages: & Melting: \\
\hline I & $\begin{array}{l}\text { Liquid } \\
\text { phase } \\
\text { sintering }\end{array}$ & \begin{tabular}{|l} 
Polymer \\
binder \\
sintering
\end{tabular} & Printing & $\begin{array}{l}\text { Laser } \\
\text { metal } \\
\text { melting }\end{array}$ \\
\hline III & & $\begin{array}{l}\text { Debinding + } \\
\text { Thermal } \\
\text { sintering + } \\
\text { Infiltration } \\
\end{array}$ & $\begin{array}{l}\text { Debinding + } \\
\text { Thermal } \\
\text { sintering + } \\
\text { Infiltration } \\
\end{array}$ & \\
\hline \begin{tabular}{|l|} 
Laser \\
power
\end{tabular} & $200 \mathrm{~W}$ & $20 \mathrm{~W}$ & No laser & $\begin{array}{c}300-500 \\
\text { W }\end{array}$ \\
\hline \begin{tabular}{|l} 
Laser \\
Type
\end{tabular} & $\begin{array}{c}\mathrm{CO}_{2} \\
\mathrm{Nd}: \mathrm{YAG}\end{array}$ & $\mathrm{CO}_{2}$ & & Nd:YAG \\
\hline $\begin{array}{l}\text { EOS } \\
\text { DMLS } \\
\text { 3D } \\
\text { systems }\end{array}$ & & & & \\
\hline ProMetal & & & & \\
\hline $\begin{array}{l}\text { F\&S, } \\
\text { Trumpf, } \\
\text { Concept }\end{array}$ & & & & \\
\hline
\end{tabular}

Table 3. Overview of the metal manufacturing systems.

For the production of metal components with SLS, we distinguish between a single stage part building, based on the liquid phase sintering process (Nyrhilä O. Pat US 5,732,323 prio. 1994) [49] [58] [96] [118] [124], and a two-stage process chain. The two stage material system is using a polymer binder that has to be debinded, after which the metal particles are thermally sintered. In the two stage processes different Micro - Joining mechanisms between the metal particles can be distinguished (Gatto A., Iuliano L. [30]). The 3D-Printing approach discussed later, is a similar two-stage process with a polymer binding type stage. Selective Laser Melting (SLM) is a metal melting based process described in a patent by Meiners W. [83] (Fraunhofer Gesellschaft) US 6,215,093 (DE 19649865 prio. 2.12.1996) and has parallels to the one-stage SLS process. An overview is given in table 3 .

Looking at the state of the research and the process models available (Abe, Glardon, Kruth, Katz) it is clear that the $\mathrm{Nd}$ :YAG laser (wavelength $1061 \mathrm{~nm}$ ) is a better choice than $\mathrm{CO}_{2}$ lasers (wavelength 10.6 $\mu \mathrm{m})$ due to the better absorption of metals for shorter wavelength, the larger parameter window, smaller spot size and higher specific power for the one-stage SLS and SLM processes [1] [5] [16] [34] [51] [60].

\section{The One-Stage SLS Process}

This process (Figure 13), also known under its commercial name Direct Metal Laser Sintering (DMLS ${ }^{\mathrm{TM}}$ ) [48] [52], is practiced with different materials (see table 4 ). One of the main issues is porosity [117], which still may call for a subsequent infiltration or/and furnace sintering.

\begin{tabular}{|c|c|c|c|}
\hline 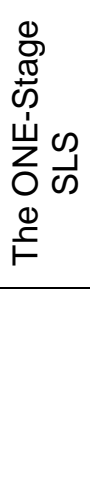 & iron & $\begin{array}{l}\text { green } \\
\text { iron / } \\
\text { liquid former(B) } \\
\text { liquid } \\
\text { spreading } \\
\text { solution } \\
\text { reprecipitation } \\
\text { solid } \\
\text { skeleton }\end{array}$ & 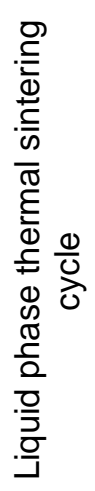 \\
\hline
\end{tabular}

Figure 13. The One-stage Liquid sintering is a portion of the practiced thermal sintering with left over porosity.

The material composition, the grain size and post treatment with shot penning have helped to some extent to reduce this problem: Figure 14. The recently introduced $20 \mu \mathrm{m}$ metal powders brings a significant improvement in mechanical properties surface quality and porosity but the productivity decreases strongly (Figure 15) [114] [115].
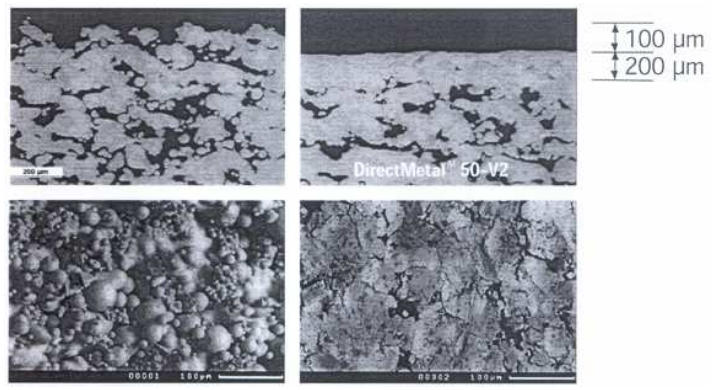

Figure 14. SLS DMLS Direct-Metal 50V-2 grain size $50 \mu \mathrm{m}$ porosity $10-15 \%$, left before right after shotpenning $Z X$ and $Y X$ plane(Source EOS). 


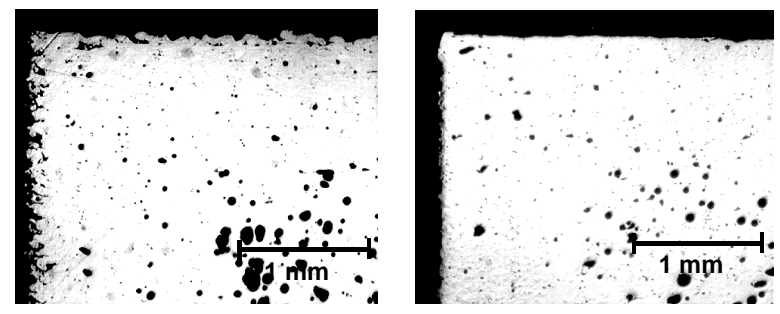

Figure 15. SLS DMLS Direct-Steel 20V-2 grain size $20 \mu \mathrm{m}$ porosity 5\%, in the ZX plane; left before right after shot-penning (Source IPT).

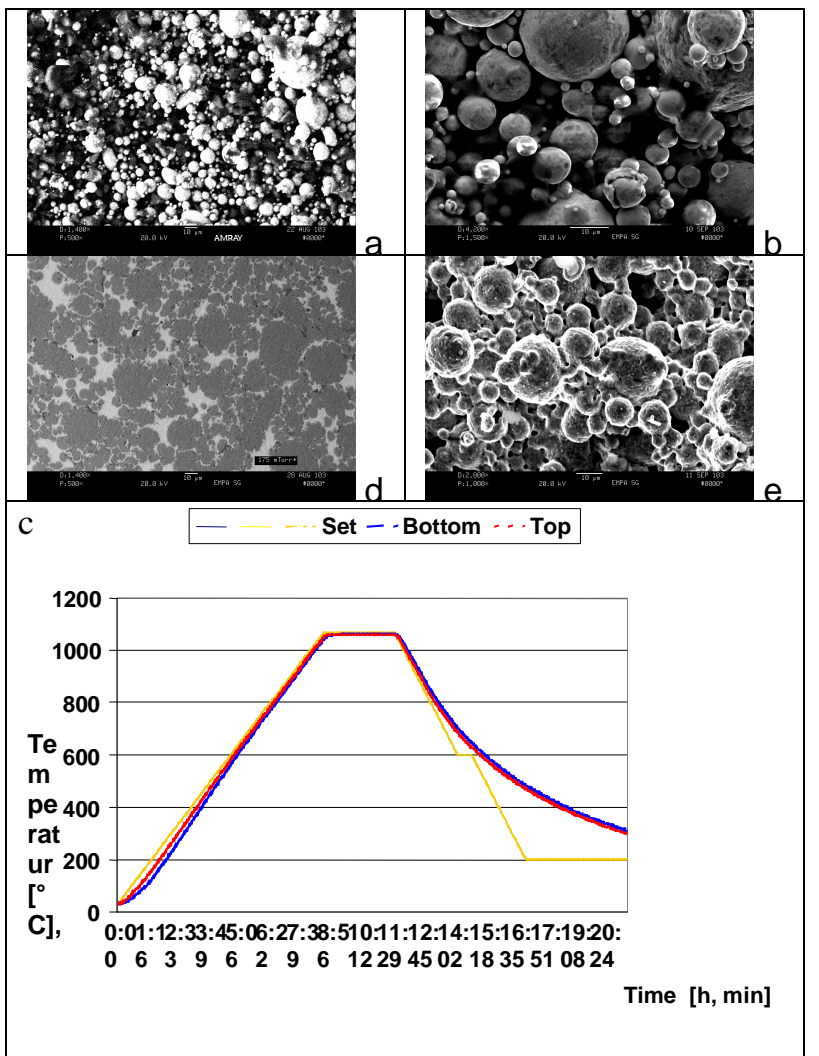

Figure 16: The 2-stage process chain: a) powder with binder, b)-green part, c) oven cycle, d) full dense part, e) necking between particles - brown (Source: FHS, EMPA).

\section{The Two-Stage SLS Process}

In the 2-stage process, laser sintering creates a green part [76]. The metallic metal powder particles are bound together with an organic binder at low temperatures and with a relatively low strength. The final properties are obtained from subsequent thermal sintering (necking) in a high temperature oven cycle followed by infiltration with bronze or copper in the same cycle. The result is a fully dense solid part (Figure 16) [27].

Similar to other RP processes, the accuracy analysis on tools and parts, produced with this process, shows a big scatter and acceptable values only for small parts (Figure 17). It is clearly near net shape manufacture. Big efforts are needed to improve this shortage.

\section{SLS Long-term consistent LM metal materials properties}

The choice of a manufacturing process is a technological decision and done in consideration of geometrical shape, quality, quantity, etc. In traditional design, the selection of the manufacturing process and of the component material are almost independent parameters or at least have a very large variation possibility for the designer. On the contrary, in LM the material and process form a dependent non-detachable selection. Thus we automatically select the mechanical properties of the part given for commercial materials in Table 4. An individual characterisation is indispensable [120]. The freedom is in the almost paramount relationship to geometrical shape and complexity.

The selection of $L M$ as a production method is prima-rily a design and not a manufacturing decision. Thus we automatically select the mechanical properties of the part when selecting the production method.

Tooling $\mathrm{x}, \mathrm{y}, \mathrm{z}$, deviations (mm)

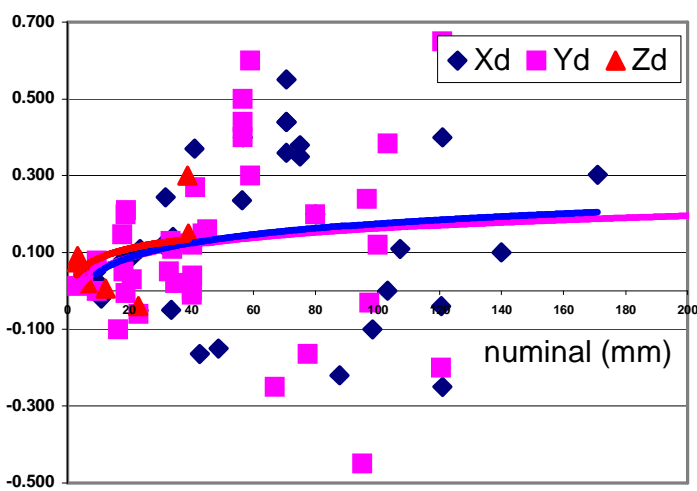

Figure 17. The accuracy analysis demonstrates the ability to manufacture near net shape parts only

(Random measurements done on different geometries and different production batches)

(Source. FHSG).

\section{Advanced material systems}

During the years, much research work was done and published, and patents were deposited, for advanced SLS metal material systems. Regrettably none have yet reached industrial maturity. The list of tried materials is long:

At IPT Aachen (D), IN 718, ZrSiO4, SiO2 was experimented [53]. At KUL Leuven (B) WC-Fe-Ni, SiC, WC-9Co and WC-12Co cermets were tried out [60][64][65][66]. Cu, Al and Ti were experimented by Osakada and Abe [4]. Bampton C.C., US patent $5,745,834$ (prio. 19.09.1995) [11], utilises powder blends containing a base metal, a lower melting temperature metal and a polymer binder. The technology called DMF (Direct Metal Fabrication), was developed at the Rockwell Scientific Centre. They report successful technology use for mild steel, stainless steel, precipitation hardened tool steel, and nickel based supper alloys and copper 


\begin{tabular}{|c|c|c|c|c|c|c|c|c|c|c|c|c|c|}
\hline & & 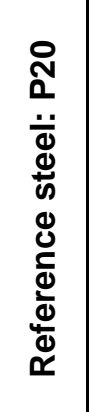 & 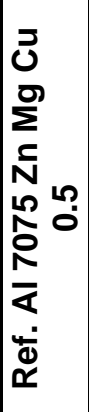 & 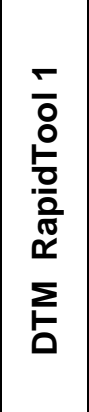 & 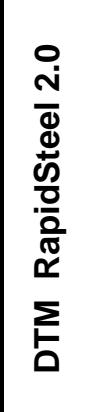 & 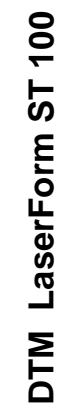 & 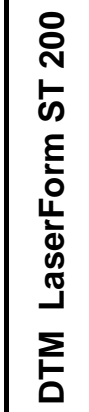 & 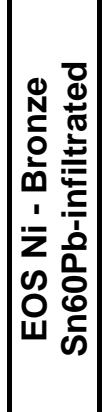 & 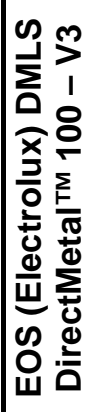 & 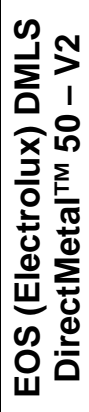 & 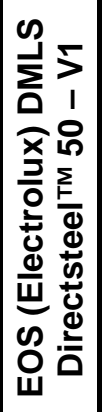 & 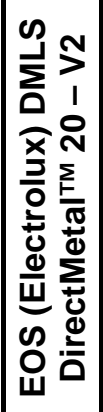 & 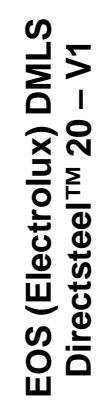 \\
\hline Grain size & {$[\mu \mathrm{m}]$} & - & - & 50 & 34 & 23 & 20 & 100 & 100 & 50 & 50 & 20 & 20 \\
\hline $\begin{array}{l}\text { Tensile } \\
\text { Strength }\end{array}$ & $\mathrm{MPa}$ & 950 & 570 & 475 & 580 & 510 & 435 & 162 & 199 & 199 & 499 & 450 & 600 \\
\hline Yield Strength & $0.20 \%$ & 751 & 502 & 255 & 413 & 305 & & 124 & n.a & n.a & n.a & n.a & n.a \\
\hline Young Modul & $\mathrm{GPa}$ & 210 & 65 & 210 & 263 & 137 & 142 & 60 & n.a & n.a & n.a & n.a & n.a \\
\hline
\end{tabular}

Table 4. To date commercialised SLS metal powder systems and their mechanical properties.

alloys. The A6 Tool Steel announced by 3D Systems might be based on the DMF technology or the II stage SLS process.

According to Stucker B.E., in US Pat. 5,870,663, the material system $\mathrm{ZrB2} / \mathrm{Cu}$ is used. for the manufacture of low wear EDM electrodes [121].

Very close to practical use is the development of aluminium alloy infiltrated with aluminium by the University of Queensland [113]. A two-step approach was implemented. Aluminium powder with organic polymer binder is selectively laser sintered. In the thermal sintering, magnesium, especially at low concentrations, has a disproportionate effect on sintering because it disrupts the passivating $\mathrm{Al}_{2} \mathrm{O}_{3}$ layer. Additives as little as $0.07 \mathrm{wt} \%$ (100 ppm) lead, tin or indium promotes sintering in an $\mathrm{Al}-\mathrm{Zn}-\mathrm{Mg}-\mathrm{Cu}$ alloy. Additionally the oven atmosphere was optimised. The infiltration is done with aluminium alloys [111] [112] [113] (Figure 19). Typical properties of SLS aluminium parts (Figure 18) are given in Table 5.

\begin{tabular}{|l|l|l|}
\hline Shrinkage & $\%$ & $<1 \%$ \\
\hline Tensile strength & $\mathrm{MPa}$ & Up to 200 \\
\hline Ductility & $\%$ & Up to $0.5 \%$ \\
\hline Furnace time & $\mathrm{H}$ & $<24$ \\
\hline
\end{tabular}

Table 5. Mechanical properties of SLS made Aluminium parts.

Trials to further improve the quality of SLS mould inserts are undertaken by applying coatings on the SLS inserts. Systematic approach and research is still missing, but the primarily results are encouraging [42].

Despite a large number of patents, research results and success claims, a real breakthrough has not happened. The chances are there. What are causing the success delay? What are the reasons for the hesitating break through? Will SLM (see
§6.2) have quicker immediate success? These are open questions for the near future.

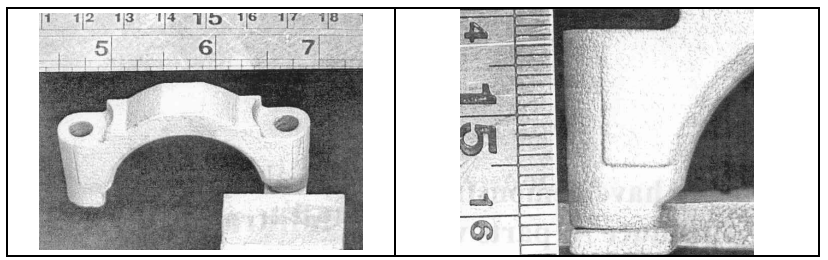

Figure 18. SLS made example of an Aluminium part (Source: 3D Systems).

\section{Some SLS manufacturing examples in metal}

Manufacturing metal parts is still limited to complex medium sized tooling inserts, but there is an evolving need and application [21] [47] [49]. It allows the production of inserts with complex parting lines and deep slots. Productivity increases, in injection moulding can be accomplished by incorporating conformal cooling channels [23] [50]. The actual high cost and low productivity of the inserts are the main reasons for the limited application [122].

\section{Three Dimensional Printing - 3DP}

E. Sachs and M. Cima from the MIT, the inventors of the 3DP process, have already published a paper on their work in the CIRP annals in 1990 [107]. The process and equipment were optimised for several applications: manufacture of ceramic (casting) shells, metallic parts, wax prototypes, rapid tooling and RM. Figure 21 describes the printing procedure for metal parts.

The process is a two-stage process (table 3 ) and suitable for large parts as well as small ones (Build volume $1 \times 0.5 \times 0.25$ meter). The multi nozzle 'drop on demand' jet printing concept on a powder bed allows a high productivity with acceptable geometrical precision. Some printing limits, defects 
and considerations are discussed by Lanzetta $\mathrm{M}$. and Sachs E. [62] [63].

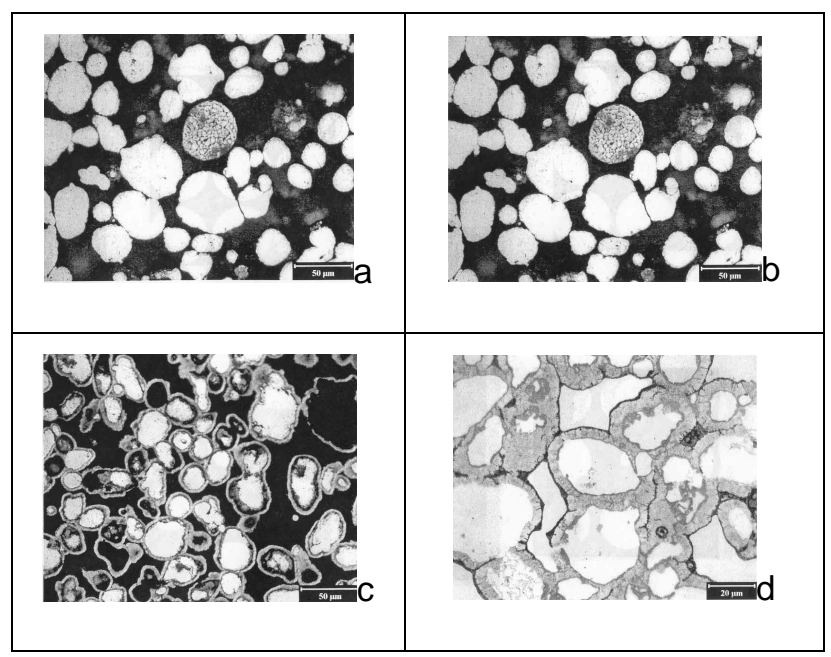

Figure 19. SLS Aluminium formation steps a) green resin bonded, b) burnout, c) skeleton, d) infiltration (Source: 3D Systems)

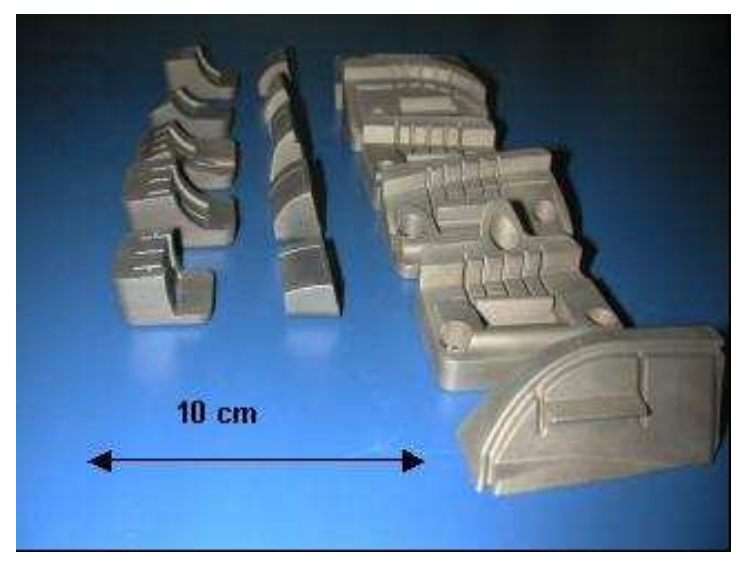

Figure 20. SLS two-stage made tooling inserts material LaserForm 100 (Source FHSG)

The material restrictions are mainly induced by the need for a subsequent thermal sintering and infiltration process [46]. In the metallic applications, stainless steel powders serve as basic stock material and a polymer low viscosity acrylic binder is used. The available metal material grades, mechanical properties and performance are given in Table 6, [7] [101].

A tooling example for Lost Foam casting patterns is presented in Figure 22. Tooling to support lost foam casting normally requires machining the mould cavity, and subsequently drilling vent holes. Using 3DP, vent holes of a diameter of $.38 \mathrm{~mm}(0.015$ ") can be directly incorporated in the mould. 1200 of these holes can be distributed in a one square foot area. This resulted in a $50 \%$ reduction of tool delivery time. Ongoing efforts in modelling and material search are reported by I Lembo and Anderson [67].

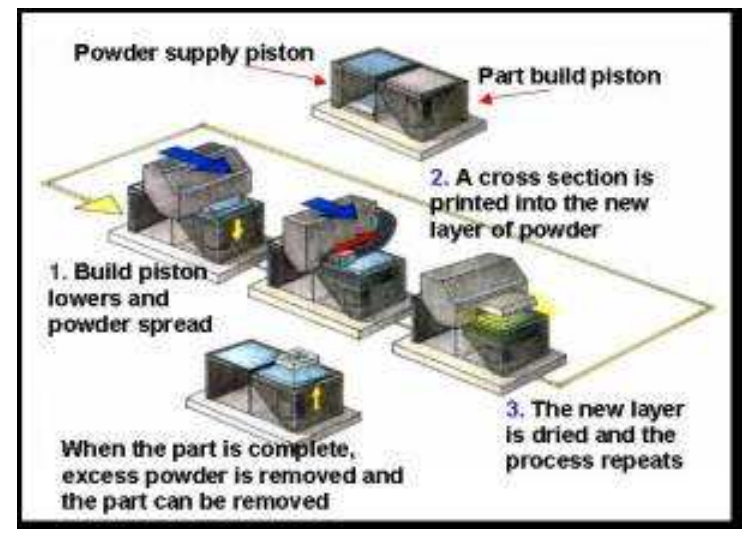

Figure 21. 3DP basic printing equipment concept and process chain the green parts are thermally sintered and infiltrated in the following steps Source : Extrudehone-Prometal.

\begin{tabular}{|c|c|c|c|}
\hline \multicolumn{2}{|c|}{ Material grade } & S3 & S4 \\
\hline $\begin{array}{l}\text { Tensile } \\
\text { Strength }\end{array}$ & $\mathrm{MPa}$ & $406 \mathrm{MPa}$ & $683 \mathrm{MPa}$ \\
\hline Elongation & $\%$ & 8.00 & 2.30 \\
\hline Hardness & HB & $\begin{array}{c}60 \text { Rockwell } \\
\text { B Nominal } \\
107 \mathrm{HBS} \\
(3000 \mathrm{kgf})\end{array}$ & $\begin{array}{c}26 \text { Rockwell C } \\
\text { Nominal } \\
258 \mathrm{HB}\end{array}$ \\
\hline $\begin{array}{c}\text { Surface } \\
\text { finish }\end{array}$ & $\mu \mathrm{m}$ & $\begin{array}{l}12.5 \mu \mathrm{m} \\
\text { Typical }\end{array}$ & $\begin{array}{l}12.5 \mu \mathrm{m} \\
\text { Typical }\end{array}$ \\
\hline Accuracy & $+/-\mathrm{mm}$ & $\begin{array}{c}+/-0.13 \mathrm{~mm} \\
+/-0.002 \\
\mathrm{~mm} / \mathrm{mm}\end{array}$ & $\begin{array}{l}+/-0.13 \mathrm{~mm}+/- \\
0.002 \mathrm{~mm} / \mathrm{mm}\end{array}$ \\
\hline $\begin{array}{l}\text { Density of } \\
\text { parts }\end{array}$ & $\%$ & 94 & 94 \\
\hline $\begin{array}{l}\text { Production } \\
\text { rate }\end{array}$ & $\begin{array}{c}\mathrm{mm}^{3} / \mathrm{ho} \\
\mathrm{ur}\end{array}$ & $\begin{array}{c}4.1 \times 10^{6} \\
\mathrm{~mm}^{3} / \mathrm{hour}\end{array}$ & $\begin{array}{c}4.1 \times 10^{6} \\
\mathrm{~mm}^{3} / \text { hour }\end{array}$ \\
\hline
\end{tabular}

Table 6. 3DP available metal material grades mechanical properties and performance.

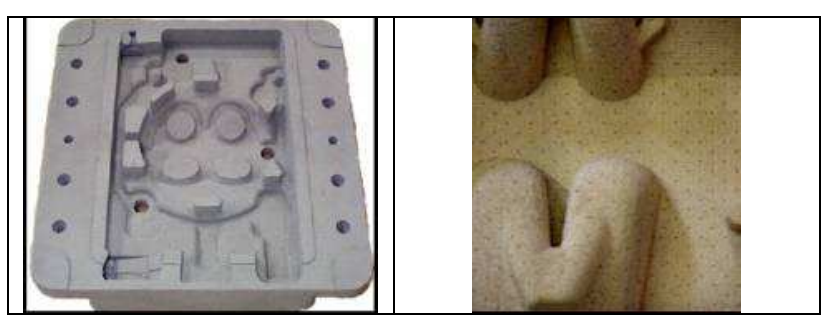

Figure 22. Lost Foam Casting: tooling for PSE (expanded polystyrene patterns) (Source : Extrudehone-Prometal).

\section{Paste-based Stereolithography - OPTOFORM}

The OPTOFORM process is a variant of the classical Stereolithography process, in which the liquid photopolymer is substituted by much more viscous polymer paste (i.e. an acrylate or epoxy photopolymer with a higher degree of pre-curing). This process, initially developed by a small French company, is now further perfected by the leading US SLA vendor. The major advantage of the process is that it not only allows one to produce plastic 
prototypes as in traditional Stereolithography, but the high viscous paste can be filled with large amounts of metal or ceramic powder material without a tendency of sedimentation. For metals, filling rates up to and even over $60 \%$ in volume (90\% in weight) are possible. Subsequently, debinding and furnace sintering is applied to yield near $100 \%$ dense metal or ceramic parts. Special kneading recoating systems and evaporating viscosity modifiers have been introduced to make the use of paste material possible [44]. The process has been demonstrated to be able to produce good quality steel, titanium and ceramic parts (Figure 23).

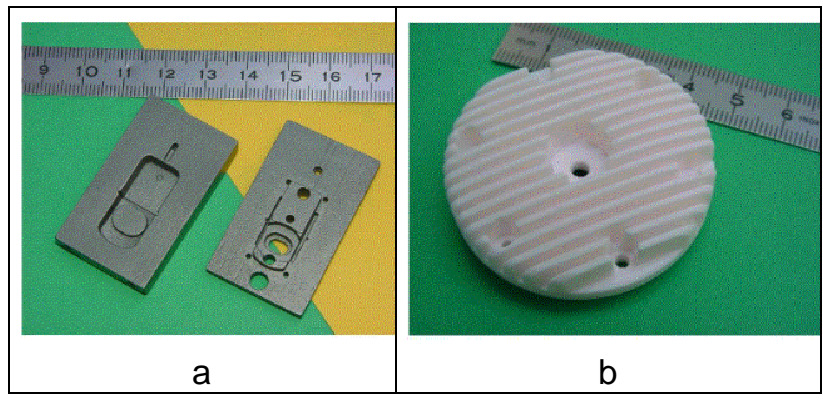

Figure 23. a)Titanium and b) ceramic part produced by Optoform-SLA (Source: CRIF/KUL).

\section{Laminated Object Manufacturing - LOM}

The Laminated Object Manufacturing concept was investigated very early (1984) by Nakagawa T. and Kunieda M. for laminated metal sheet for tooling [92] [93]. The technology has made progress since then. Two advantages are inherent: the process is suitable for medium and large sized parts and secondly it is almost irrelevant what material is used (paper, plastics and metals are often applied). It is hence of considerable interest for car and instrumentation applications.

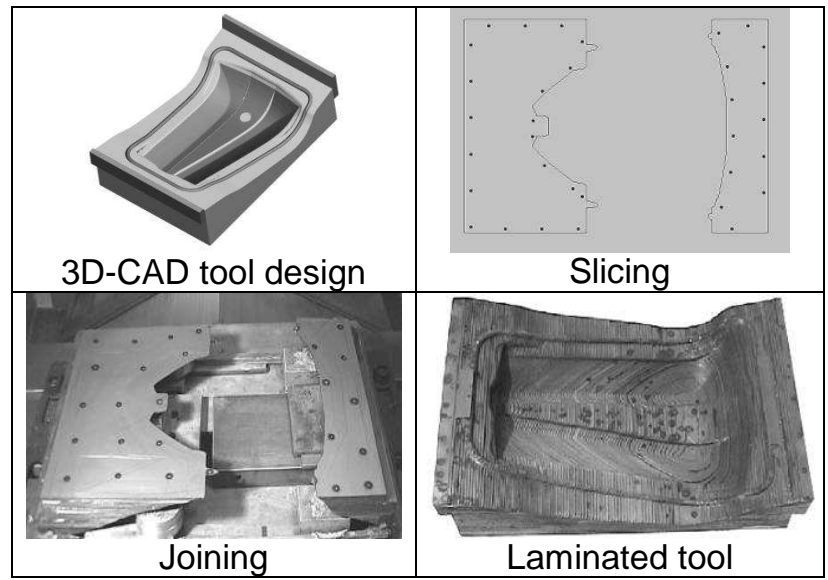

Figure 24. the principles steps in the LOM process chain.

Figure 24 describes the steps in LOM. Recently, the process was refined taking advantage of progress in laser technology, IT and design optimisations. The adaptive slicing is a recent step forward. The tool is divided into an inner and outer module, according to the topology. Anchors and/or screws are designed permitting the selection of the optimal slicing direction, reducing final machining costs and allowing a modular extendable design for product variations (Figure 25) [43].

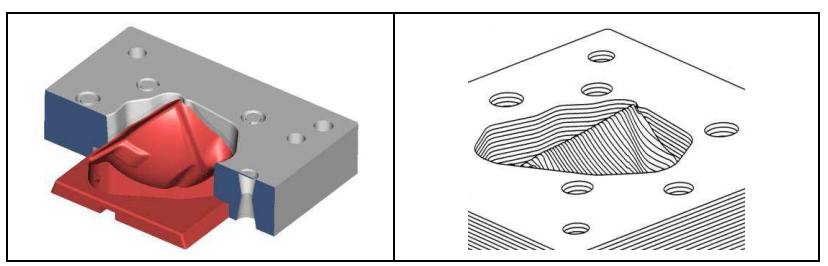

Figure 25. Adaptive slicing from Metal Laminated Tooling by Multiple Laser Processing - MELATO www.iws.fhg.de/ melato (Source IWS).

Layer joining is a critical step in the process; it determines the strength in the direction perpendicular to the layers and has great influence on the functionality of the final tool and the economics of the process. Layer diffusion welding is shown in Figure 26. Steel soldering with copper solder and ultrasonic consolidation of aluminium foil is shown in Figure 27 [26] [129]. Several joining options together with their respective applications are given in Figure 30 [43].

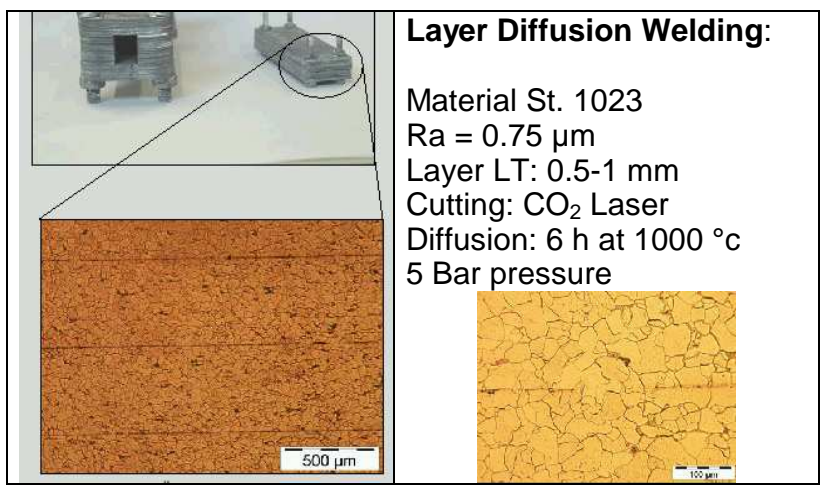

Figure 26. Layer diffusion welding: layer boundaries visible, local interlayer grain produces a solid part (Source: LFT; BLZ).

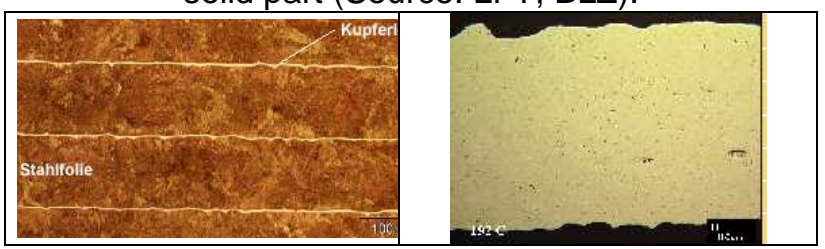

Figure 27. Soldering with cupper solder (left)

[Temperature: $1120^{\circ} \mathrm{C}$, duration $1 \mathrm{~h}$, with surface pressure] (Source: LFT; BLZ) and ultrasonic consolidation (right) of Aluminium $0.1 \mathrm{~mm}$ layer thickness (Source Solidica).

Main applications are sheet metal forming tools. An example of a forming tool for a floor panel (Figure 28 ) was compared with conventionally produced $\mathrm{Zn}$ dies and illustrates interesting benefits (Table 7). Applications in other areas (e.g. plastic injection moulds) are known on an experimental basis only and can be found in publications. [61]

\subsection{Melting LM processes}

As shown in Figure 11, LM melting processes use powder stock material in two ways: layer spread on 
the machining melting area or coaxial delivery with the energy source. Another implementation uses wire formed stock materials.

\begin{tabular}{|c|c|c|c|c|c|c|c|c|}
\hline & $\begin{array}{l}\frac{5}{0} \\
\frac{0}{8} \\
\frac{0}{0}\end{array}$ & 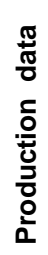 & $\begin{array}{l}\frac{\pi}{\pi} \\
\frac{\pi}{0} \\
\Phi \\
\frac{0}{\omega}\end{array}$ & 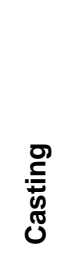 & 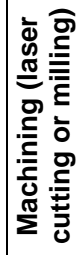 & 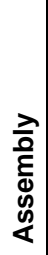 & 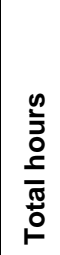 & \\
\hline $\begin{array}{l}\text { Laminate } \\
\text { Dies } \\
\text { Thickness } \\
0.5 \mathrm{~mm}\end{array}$ & 50 & 30 & 10 & 0 & 40 & 30 & 160 & $\begin{array}{l}\text { Laser cutting } \\
2.7 \mathrm{~m} / \mathrm{min}\end{array}$ \\
\hline Zn Dies & 50 & 30 & 120 & 160 & 40 & 60 & 460 & $\begin{array}{l}\text { Die: Zn } \\
\text { Punch: Zn + } \\
\text { NC (Milling) }\end{array}$ \\
\hline
\end{tabular}

Table 7. Time comparison of LOM and $\mathrm{Zn}$ die for floor panel die production (Source: Sekisou Kanagata Co.).

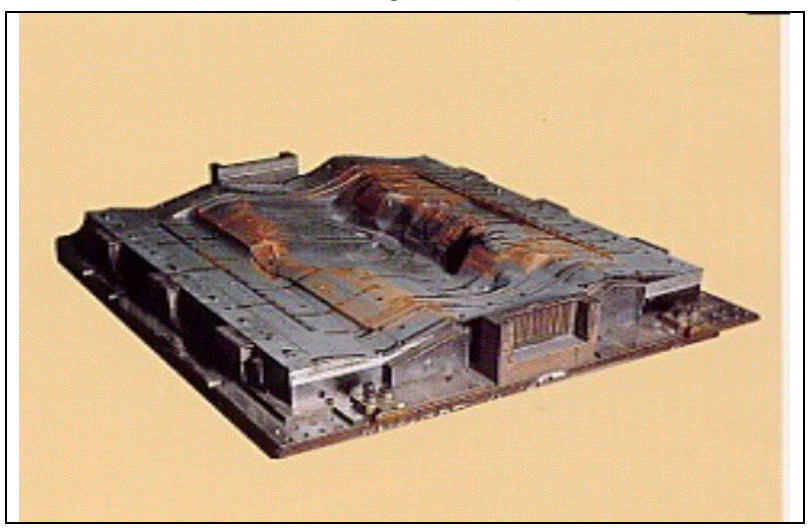

Figure 28. Forming Tool for Floor Panel RT by Laser Cut Metal Sheet Lamination (Source: Sekisou Kanagata Co.).

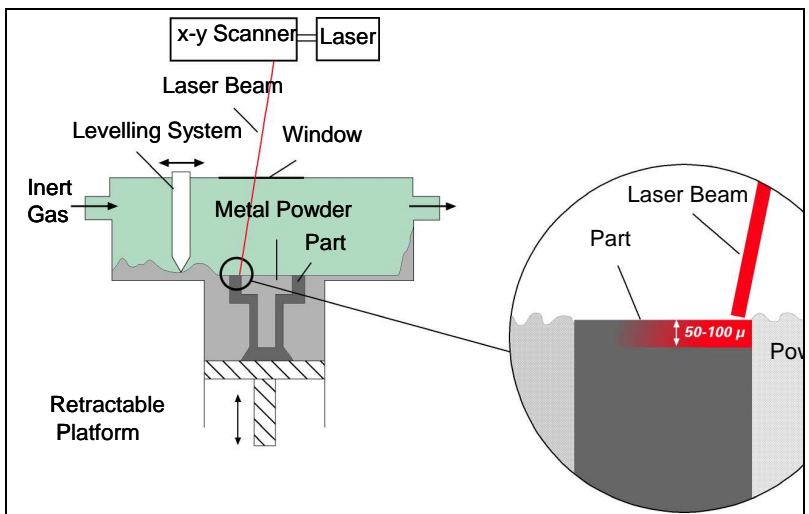

Figure 29. The SLM system principle: layer thickness $0.05-0.1 \mathrm{~mm}$; Laser Nd:YAG wavelength $1064 \mathrm{~nm}$ (Source ILT, MCP).

\section{Selective Laser Melting - SLM}

The selective laser melting process is described in US Patent 6,215,093 as follows: "The method is characterised in that the metallic material in powder form is applied in the form of a metallic powder free of binders and fluxing agents, that it is heated by the laser beam to melting temperature, that the energy of the laser beam is chosen in such a way that the layer of metallic powder is fully molten throughout at the point of impact of said laser beam" [83] [84].

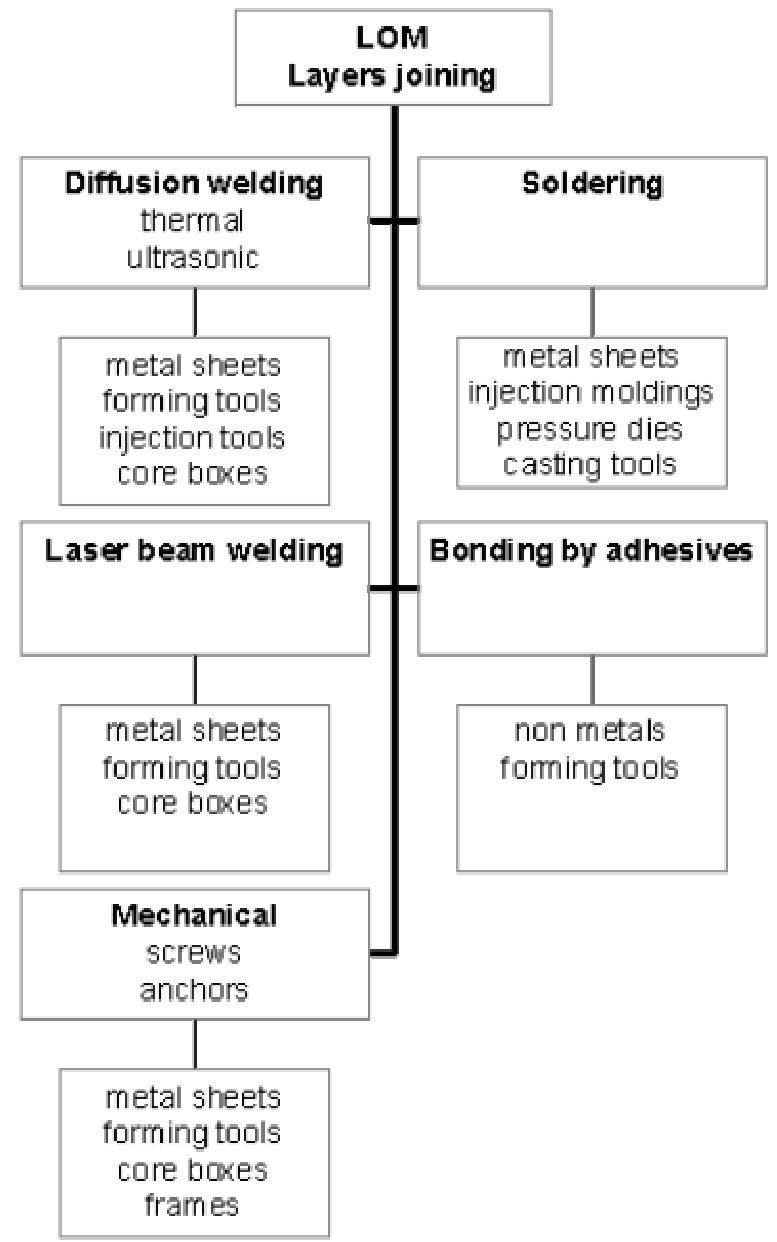

Figure 30. LOM layer joining options and typical practice (Source IWS).

The equipment is similar to the SLS process (Figure 29). However, the material is completely melted by the laser beam guided by a scanner. It has similarities with welding techniques. Its most significant advantage is the independence with respect to material selection. All typical metals may be thought as candidate material and most probably perform well under optimised conditions. Most available SLM systems use a Nd:YAG laser, in total congruence with the results of SLS modelling [16] [90] [116][127].

The parts reach near full density and have mechanical properties comparable to bulk material as shown in Figures 31 and 32 . Notice that a significant reduction in ductility occurs. This phenomenon is well known in welding technologies and could be corrected with thermal treatments. Other experienced material data is given in Table 8 [2] [3] [82] [98].

Other material systems including Titanium for the manufacturing of parts and medical implants were experimented under similar conditions [4]. Some application examples are shown in Figure 33. 


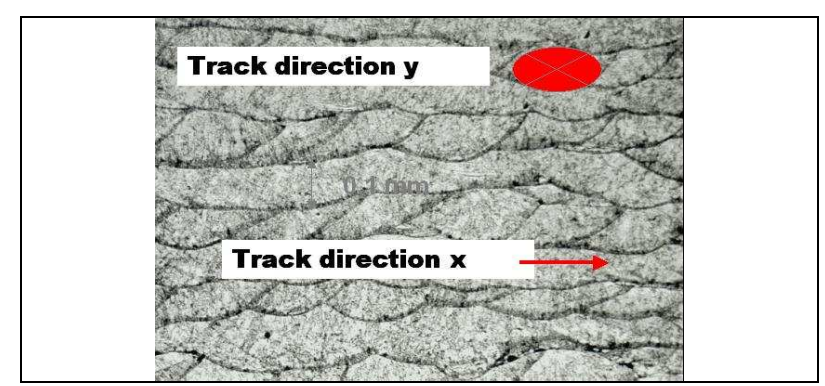

Figure 31. Micrograph showing completely compact cross-section with $X$ and $Y$ tracks made in stainless steel $316 \mathrm{~L}$ (scanning strategy: alternating $90^{\circ}$ direction) (Source ILT, MCP).

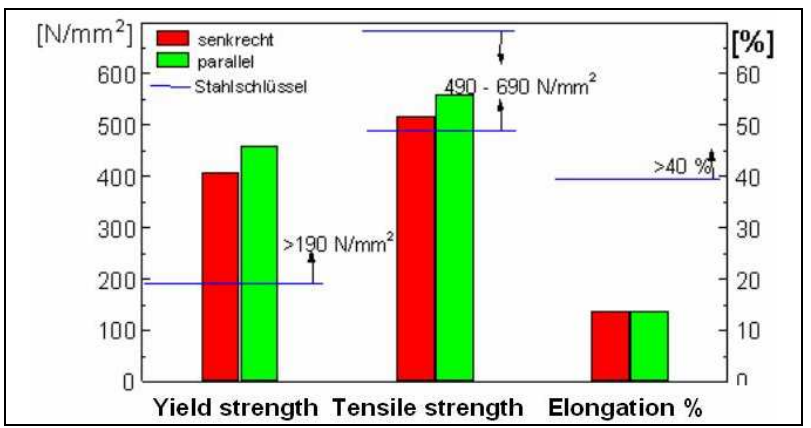

Figure 32. Comparison of SLM strength properties to the standard bulk material for stainless steel 1.4404 (Source ILT).

\begin{tabular}{|l|c|c|c|c|}
\hline \multicolumn{2}{|c|}{ Material grade } & $\begin{array}{c}\text { Stainless } \\
\text { Steel } \\
1.4404\end{array}$ & $\begin{array}{c}\text { Tool } \\
\text { Steel } \\
1.2343\end{array}$ & TiAl6V4 \\
\hline $\begin{array}{l}\text { Tensile } \\
\text { Strength }\end{array}$ & $\mathrm{MaP}$ & $480-520$ & $780-840$ & $\begin{array}{c}1200- \\
1400\end{array}$ \\
\hline Elongation & $\%$ & $10-15$ & $2-3$ & $1-2$ \\
\hline Hardness & $\mathrm{HB}$ & $\begin{array}{c}220-250 \\
\mathrm{HV} 0.1\end{array}$ & $\begin{array}{c}50-54 \\
\text { Rockwell }\end{array}$ & $\begin{array}{c}380-420 \\
\mathrm{HV} 0.3\end{array}$ \\
\hline $\begin{array}{l}\text { Surface } \\
\text { finish }\end{array}$ & $\mu \mathrm{m}$ & $\begin{array}{c}\mathrm{Rz} 30- \\
60 \mu \mathrm{m}\end{array}$ & $\begin{array}{c}\text { Rz } 30- \\
60 \mu \mathrm{m}\end{array}$ & $\begin{array}{c}\mathrm{Rz} 30- \\
60 \mu \mathrm{m}\end{array}$ \\
\hline Accuracy & $+/-\mathrm{mm}$ & $<0.1 \mathrm{~mm}$ & $<0.1 \mathrm{~mm}$ & $<0.1 \mathrm{~mm}$ \\
\hline $\begin{array}{l}\text { Maximal } \\
\text { work-piece } \\
\text { size }\end{array}$ & $\mathrm{X} ; \mathrm{Y} ; \mathrm{Z}$ & $\mathrm{n} . \mathrm{a}$. & $\mathrm{n} . \mathrm{a}$. & $\mathrm{n} . \mathrm{a}$. \\
\hline $\begin{array}{l}\text { Density of } \\
\text { parts }\end{array}$ & $\%$ & $\mathrm{ca} .100 \%$ & ca. $100 \%$ & ca. $100 \%$ \\
\hline $\begin{array}{l}\text { Production } \\
\text { rate }\end{array}$ & $\mathrm{mm} / \mathrm{hr}$ & $\mathrm{n} . \mathrm{a}$. & $\mathrm{n} . \mathrm{a}$. & n.a. \\
\hline
\end{tabular}

Table 8: SLM available metal material grades mechanical properties and performance.

The accuracy was improved by almost one order of magnitude by Concept Laser $\mathrm{GmbH}$ to values below $0.04 \mathrm{~mm}$ by implementing a system with linear drives positioning the scanner. The $X-Y$ linear motor driven axes are used in combination with a YAG laser source [91]. The new implemented ideas are well described in Herzog's Patent WO 02/36331 A2 priority 30.10.2001 (see Figure 34) [39] [40].

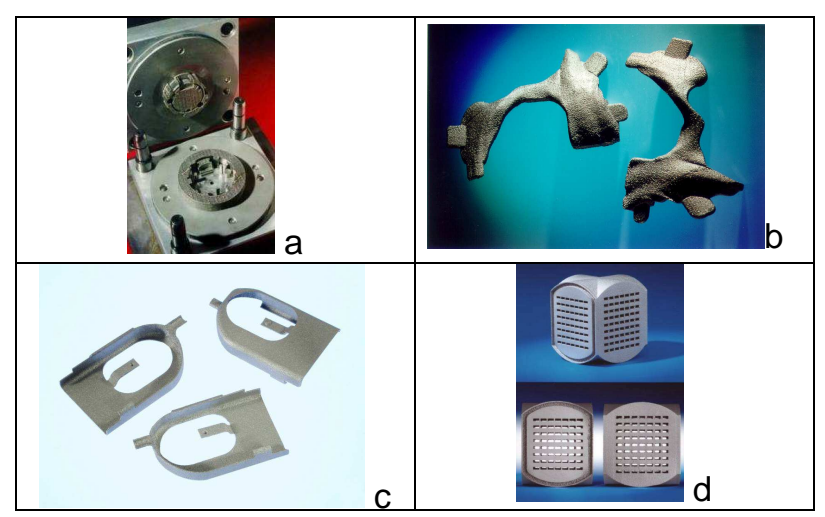

Figure 33. Some SLM examples: a) Injection tool $\mathrm{Rz}=25 \mu \mathrm{m}$, b) Titan implant, c) Thin walled $0.5 \mathrm{x}$ $40 \times 40 \mathrm{~mm}$ stainless parts, d) Heat exchanger slots $2.5 \times 1 \mathrm{~mm}$, stainless (Source ILT, MCP, FS).

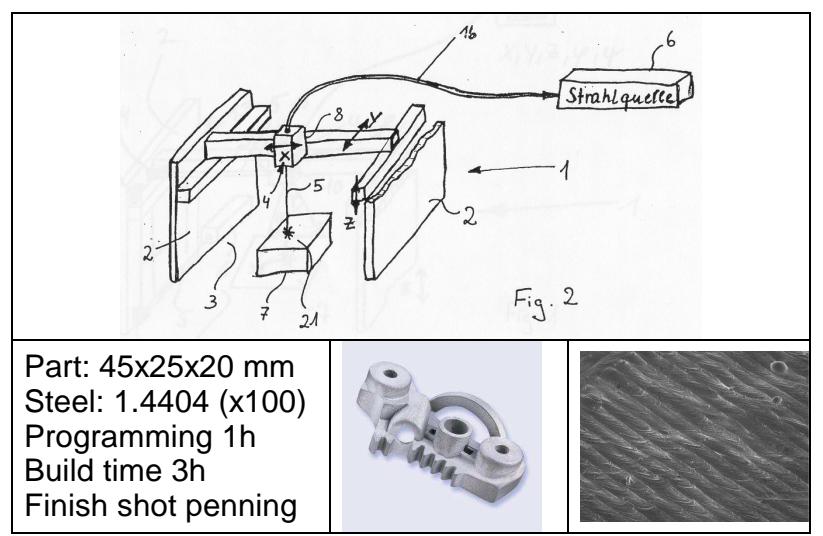

Figure 34. Herzog Patent WO 02/36331 replacing the scanner mirrors with linear $\mathrm{X}-\mathrm{Y}$ drives (Source: CONCEPT Laser $\mathrm{GmbH}$ ).

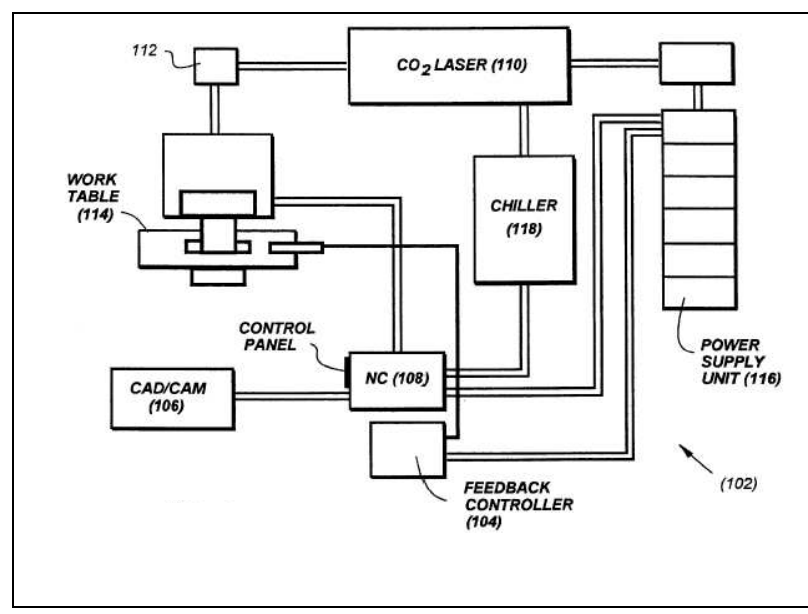

Figure 35. DMD Laser Cladding System including a Feedback controller.

The accuracy improvements were approached differently by Koch and Mazumder [54]. A closed loop feedback controller system was developed (Figure 35). An optical sensor measures the layer height and controls the laser duty cycle. The duty cycle is used to control powder flow rate. The laser cladding system DMD ${ }^{\mathrm{TM}}$ (Direct Metal Deposition) is described in US Patent 6,122,564 and US Patent $6,518,541$. The systems can be used also as multi 
material system for local alloying. It uses a $5 \mathrm{KW}$ $\mathrm{CO}_{2}$ laser source.

A further realized option is the replacement of the laser heat source with an electron beam source operating in a vacuum chamber (Figure 36) [124] [57]. During the process, paths are traced by an electron beam gun that melts the metal powder. The advantages are the higher beam efficiency and protective working chamber [8].

\section{Controlled Metal Build-up (CMB) and Laser Engineered Net shape (LENS $\AA$ )}

CMB and LENS $\AA$ are similar processes derived from welding, micro welding and laser cladding technologies. The energy sources is usually a laser beam with a coaxial or lateral delivery system of metal powder or metal wire. The material is deposited in a molten state, layer-by-layer on to the previous molten layer. The spot may be controlled by an appropriate sensor. The process is characterised by a wide range of applicable materials.

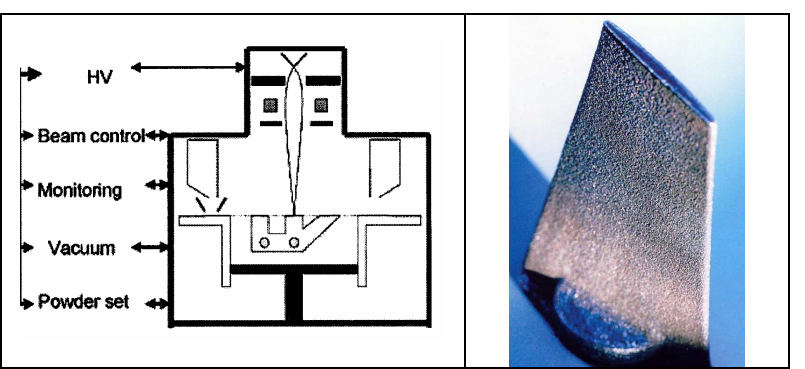

Figure 36. Principle of electron beam sintering from CAD to metal technology. Pat: PCT WO 01/81031 A1 (Source Arcam AB).

LENS $\AA$ was developed at Sandia National Laboratories and is being commercialised by several partners (appendix 1). Process details are given in [36]. Residual stress, warping and hardening are typical issues for which attempts are being made to minimise by in-situ monitoring and modelling [125].

These processes may be classified as near net shape processes since their limited spatial resolution or accuracy calls for post-processing, either by intermediate milling after each or after a set of layers are deposited, or by final milling once the whole part is built up. The absence of a full powder bed surrounding and supporting the part yield restrictions to the shape complexity and the possibility to generate overhangs. This can be solved by applying a 5-axis LM machine or by depositing separate support material around the part and combining this with 5-axes milling [102]. The greatest advantage of laser cladding processes is their unbeaten ability to produce gradient materials by applying different powder delivery nozzles that allow to gradually switch from one material to another, which is a unique feature that is of great interest to designers.

For Aeronautical applications, the AeroMet Lasform ${ }^{\text {SM }}$ process is used. Commercially procured materials are used and create fully dense machining pre-forms which require only modest machining (e.g. from $0.5 \mathrm{~mm}$ to $1.3 \mathrm{~mm}$ ) prior to use. Because the precursor material is in the form of metal powders, it is also possible to produce "graded alloys" across the geometry of a component via realtime mixing of elemental constituents, which is a very unique feature that is of great interest to designers. Since the AeroMet process takes place in an inert environment, it is possible to produce laser forms in niobium, rhenium and other materials, which require protective processing atmospheres. $A$ part in Ti-6Al-4V and a comparison of fatigue crack propagation with wrought plate is shown in Figure 37.

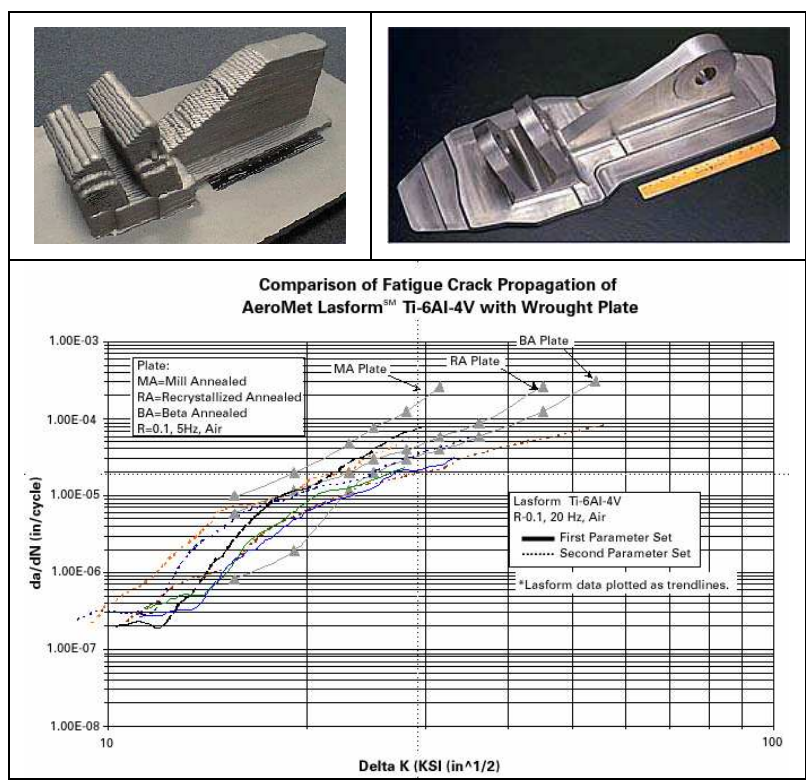

Figure 37. Part performed and final machined part material Ti-6Al-4V and comparison of fatigue crack propagation with wrought Ti-6Al-4V plate (Source: AeroMet Lasform ${ }^{\mathrm{SM}}$ ).
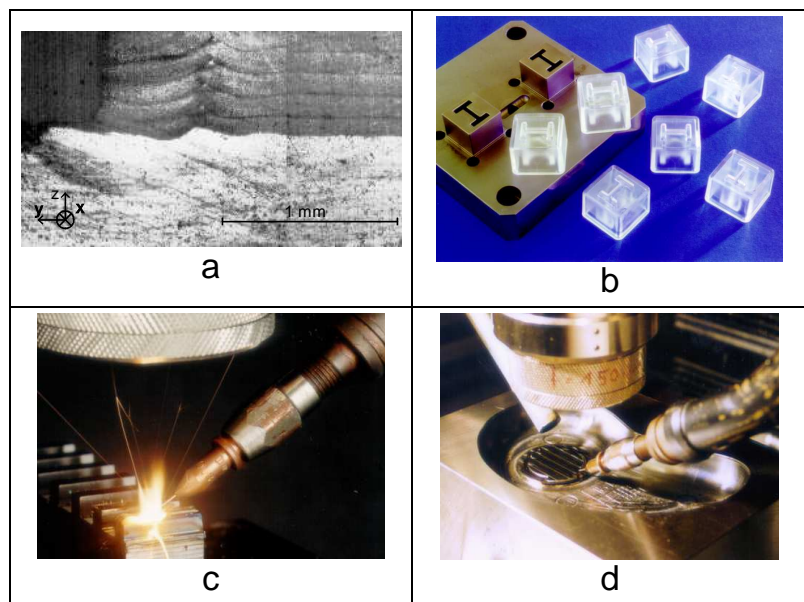

Figure 38. CMB wire process: a) micrograph of layers in the $Z$ direction on substrate (steel wire 1.2343), b) mould insert and parts, c) and d) mould repair (Source: IPT).

For tooling production and tooling repair applications 'two systems, a wire and a powderbased system, were investigated by the Fraunhofer IPT and A. Röders GmbH in Germany in 1995 [28], with the following specifications:

- Powder: Laser Nd:YAG, wavelength: 1064 $\mathrm{nm}$, power $300 \mathrm{~W}$, material: 1.2314; 
Wire: Laser Nd:YAG, wavelength: $940 \mathrm{~nm}$, power 1200 W, materials: 1.2343, 1.2709 (Figure 38).

The IMTI in Canada is working on Free Form Laser Consolidation (LC), focusing on materials and thin walled parts with high integrity [131]. Materials used: IN 525, stainless steel 316 L, Stellite 6, M4 and CPM-9V tool steel. The LC IN 625 and $316 \mathrm{~L}$ are stronger than the respective cast materials and comparable to wrought materials. Attention was paid to internal residual stresses (Table 9 ).

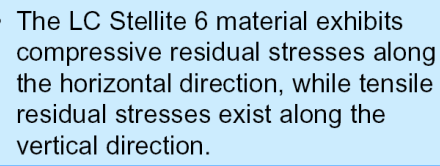

The LC Stellite 6 material exhibits compressive residual stresses along the horizontal direction, while tensile residual stresses exist along the vertical direction

\begin{tabular}{|c|c|c|}
\hline \multirow{2}{*}{ Method } & \multicolumn{2}{|c|}{ Residual Stress (MPa) } \\
\cline { 2 - 3 } & $\begin{array}{c}\text { Horizontal } \\
\text { Direction }\end{array}$ & $\begin{array}{c}\text { Vertical } \\
\text { Direction }\end{array}$ \\
\hline X-Ray Diffraction & -65 & +180 \\
\hline Hole-Drilling & -110 & +150 \\
\hline
\end{tabular}

Table 9. LC Stellite 6- Residual Stresses (Source: IMTI-NRCC).

\section{Precision Metal Deposition - PDM (FDM)}

$\mathrm{PMD}^{\mathrm{TM}}$, Laser Precision Metal Deposition, is a recently introduced metal layer wire cladding $R P$ system invented by Rabinovich: Figure 39 [103] [104]. This patented process uses an energy source to simultaneously melt and fuse a solid metal flat wire to a substrate. This is accomplished without a need to create a molten pool of metal on the workpiece prior to deposition, unlike other metal deposition systems (e.g. CMB). As a result, the metal deposition process produces metal parts with an order of magnitude less heat input into the part. Deposition accuracy $\pm 0.13 \mathrm{~mm}$ ( $0.005 ")$ and part accuracy $\pm 0.05 \mathrm{~mm}$ (0.002").

\section{DIRECT MANUFACTURING OF CERAMIC PARTS}

An important future application of LM will probably be the manufacture of ceramic parts [108]. It is predesignate since these materials are often available in powder form, while the sizes and quantities fit well in with the RP scope. Normally initial forming is done on RP equipment while the required firing happens in a second stage. Ceramic LM is still lagging behind. However, as indicated before, SLS and Optoform, for example are going in that direction. Numerous possible applications exist in the electronics and medical branches for instance. At this time we only mention one dedicated system. This dedicated SLS-like system, with a high temperature chamber reaching up to $900^{\circ} \mathrm{C}$, is shown in Figure 40. The compacted powder layer is preheated to a temperature close to the temperature of solid phase sintering and the laser energy contribution (YAG 40 Watt) is sintering the layers. After the part is completed a post sintering operation is accomplished to obtain the specified characteristics. The system was developed at the Ceramic Technology Transfer Centre, CTTC, in France.

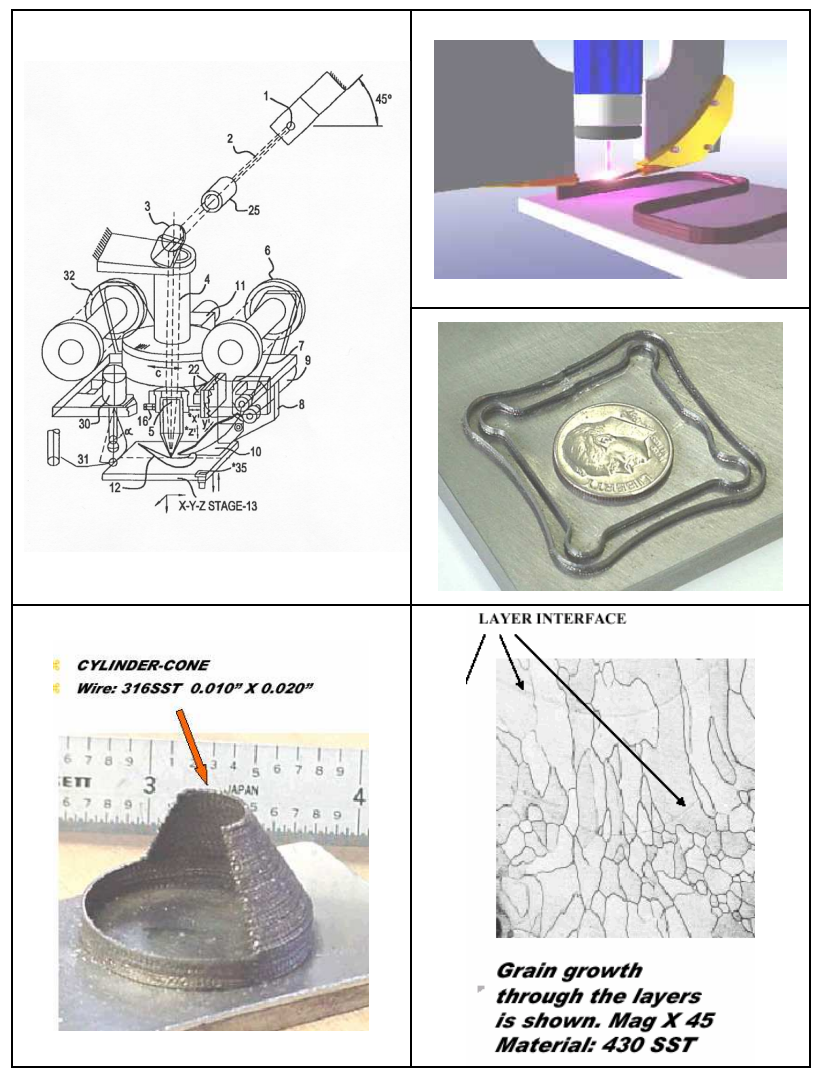

Figure 39. Laser precision metal flat wire deposition. Source: H\&R Technology Inc. US pat. 6,459,069 B1.

\section{DIRECT MANUFACTURING OF PLASTIC PARTS}

Most frequently, polymer components in medium and large quantities are manufactured 'indirectly' by injection moulding: i.e. part manufacturing can only occur through and after manufacture of a mould. In this contex, the Rapid Metal Tooling processes, described in previous sections, are of great interest, enabling throughput time reduction and new tool designs. Optionally, the tools can be produced with the process chains described in [75] [95] [99] [105]. Novel micro injection tools and technology [35] [81] are further serious options for small components.

For the direct production of polymer components, traditional cutting processes, as milling or turning, seldom offers a viable solution due to the complex, thin-walled geometry of most plastic products. They are economical only for extreme cases of low to medium quantity and simple geometry. LM technologies, however, may offer a solution.

The development of new materials and availability of long-term consistent polymer materials for classical $\mathrm{RP}$ technologies is the key to success using LM as the first choice process chain for the direct production of polymer parts. Geometrical complexity and smaller component size are main incentives. The main parameters determining the preferred process choice and possibilities are: quantity, size, complexity (Figure 41). 


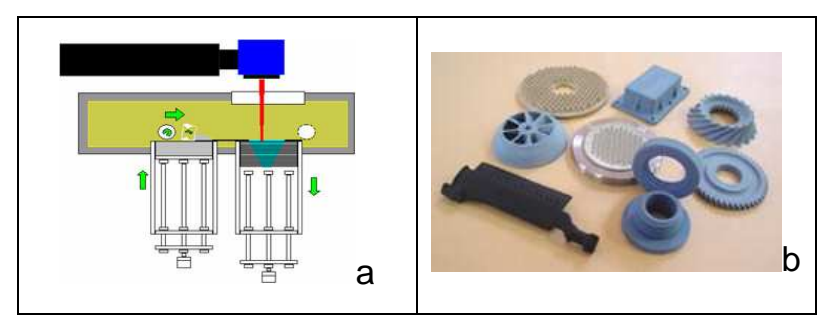

Figure 40. Ceramic manufacturing LM system a) principle with chamber temperature up to $900{ }^{\circ} \mathrm{C}$ with YAG:Laser b) typical ceramic parts after post processing (Source: Phenix Systems).

Here, the state of the art is rather obvious, as some actual examples demonstrate. However, the opportunities are much wider. For instance, SLS offers unlimited geometrical possibilities, since no support is required and part orientation can be selected freely without the need for jigs or fixtures.

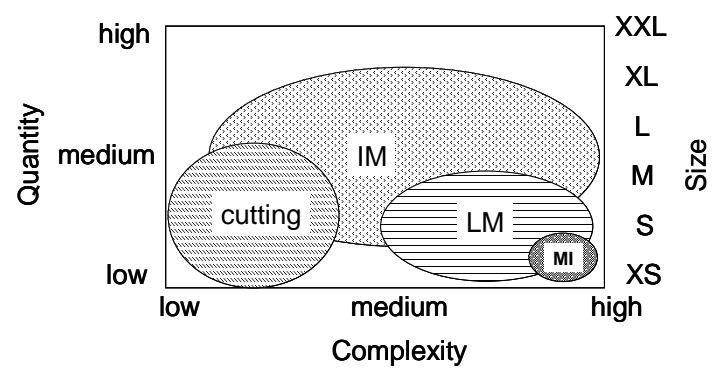

Figure 41. Positioning for plastic part manufacturing: LM - Layer Manufacturing; MI Micro Injection; IM - Injection Moulding.

This process starts with a polymer powder and can create complex long-term consistent parts in an economical way. The production of undercuts is entirely feasible. New geometries, unable to be produced up to now, may be accomplished and may lead to new features such as light weight assemblies. Design for LM (DLM) possibilities might be a new challenge!

Research efforts for these applications are in developing sustainable new materials and modelling of the process behaviour [15] [19] [60] [126]. New options in material mixtures or blending [17] [22], or locally controlled component properties as for biomedical application, are being developed [31] [37].

The broad existing plastics assortment delivers many future candidates. Commonly used technical materials like HDPE, POM, ABS, EPDM or specific application dedicated materials, e.g. PEEK for medical applications, are at the laboratory research stage.

Future opportunities are the multi-material systems. Gibson [32] describes various methods for developing the SLS polymer-based Rapid Prototyping (RP) process to include multiple materials. Three specific approaches are discussed along with current findings. Two approaches discuss adaptation of the SLS process to create heterogeneous models. The third approach discusses how the selective addition of a second material to the process can improve the overall properties of SLS components. The term "Functional Gradient Multiple-Material" (FGM) is used (Figure 42).

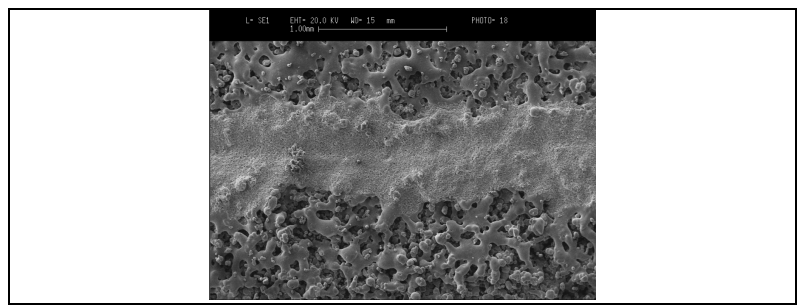

Figure 42. SEM photo of sintered DuraForn

Polyamide sintered at LP $10 \%$ with an electrical conductive path drawn on top of it

(Source: Gibson).

The broad existing polymer assortment delivers many future candidates. A system successfully applied for the development of the commercial available PA-12 (DuraForm ${ }^{\mathrm{TM}}$ ) and PS (CastForm ${ }^{\mathrm{TM}}$ ) materials is described in [72] [74]. The influencing parameters are many and the final material properties are inferior to the injected polymer grade, due to porosity and only partial melting.

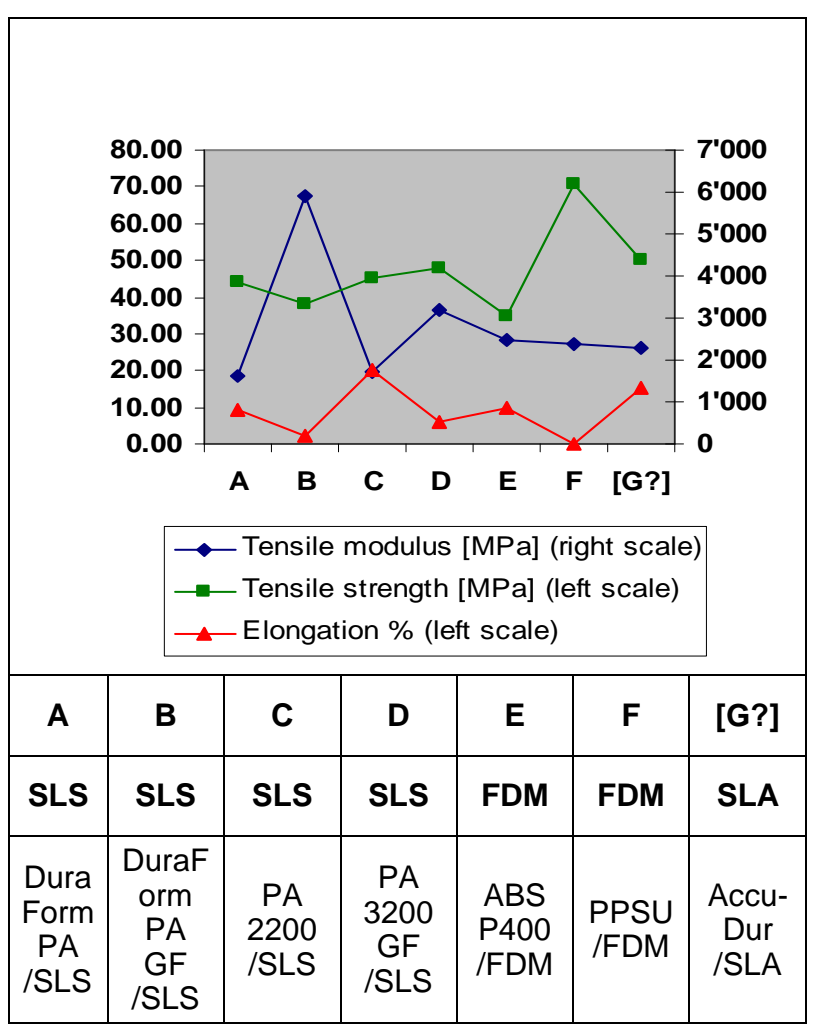

Figure 43. Long term consistent polymer materials for LM manufacturing.

\subsection{Long-term consistent LM polymer materials properties}

The availability of long term consistent polymer materials is a key issue. Figure 43 summarises the actual available grades and major mechanical properties. Many other materials are under development as for example an Elastomer EPDM 
polymer at the FHS St. Gallen Switzerland; however its lasting usability has to be proven.

The process performance like productivity, consistency, accuracy, etc., features well controllable in conventional manufacturing, have to be improved in LM simultaneously with the materials issue in order to be attractive.

\subsection{Some Manufacturing examples in Polymers}

\section{Medical}

Combining two important features mentioned before, i.e. geometrical complexity and individual customisation in a production line, it became economically possible to replace former semi manual processes for the production of hearing aids by LM [41] [80]. The shape of the hearing aid casing is made by SLS to fit the shape of the patients internal ear (Figure 44). Obviously, the material issue is of main concern. In this case, pigmented PA 12 (Nylon) fulfils all requirements including mechanical properties and skin compatibility. Several patents have been deposited for this application.

A second success story is in the dental medicine (Align Company). The process starts by digitising the impression of a dental teeth jaw (Figure. 45). The individual teeth correction is calculated step by step with appropriate propitiatory software. For each correction stage (about 12) the new modified impression is exported as a solid design. The intermediate impressions are produced on an SLA system serving as tooling for thermoforming a set of biocompatible transparent plastic bridges. By wearing the bridges in the mouth, teeth alignment is achieved stage by stage. It is customized tooling manufacturing and indirect bridge production. Direct manufacturing of the bridge is prevented by lack of suitable SLA resin [20].

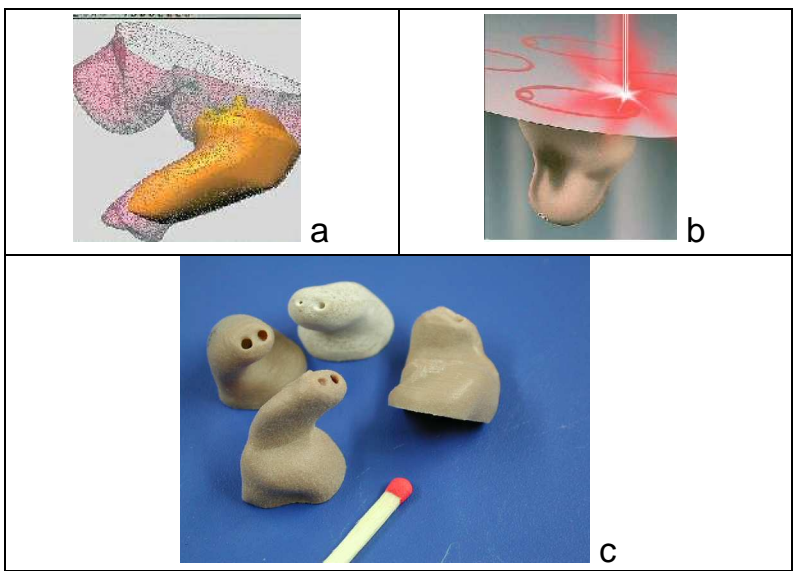

Figure 44. Production of nylon casings for hearing aids by SLS a) digital data from a wax imprint b) SLS i60-80 per layer c) pigmented shells with hearing and vent channels before and after finishing.

(Source: Siemens/Phonak/Materialise)

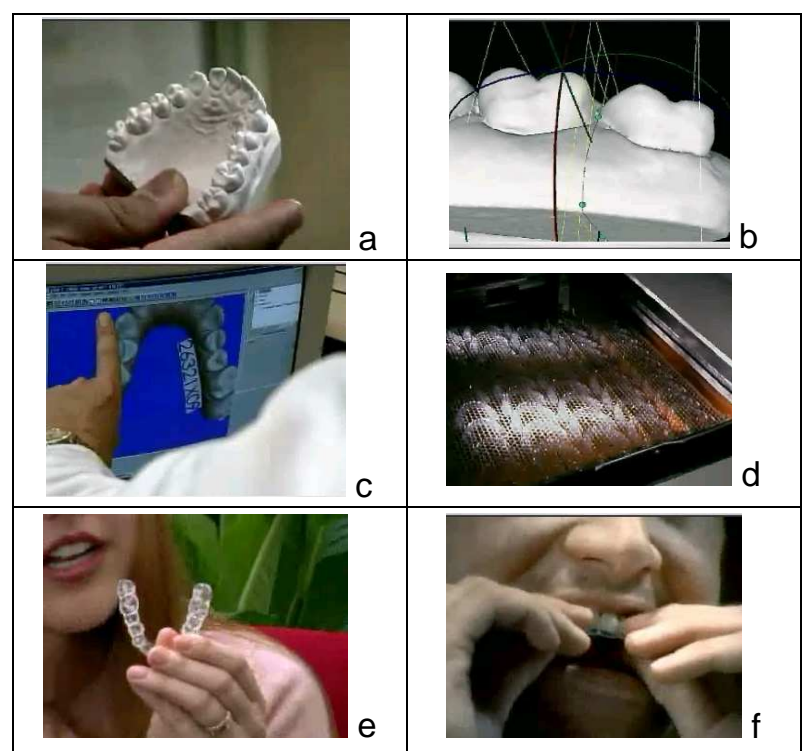

Figure 45. Individual set manufacturing process chain for each patient: a) dental impression, b) digitised data elaboration, c) STL forming tool data, d) tooling sets on SLA 7000 system, e) thermoformed biocompatible transparent plastic bridge, f) bridge use in mouth (Source: Align Company).

\section{Technical}

Boeing Co. has established an entity 'Production On Demand'. Air ducting for the aerospace industry is manufactured by SLS within hours on a Vanguard SLS System (Figure 46). Complex components that are difficult to manufacture via traditional technologies are quickly manufactured on that system, at lower cost and in fewer segments. The required material characteristics were met with a $P A$ 11 derivative with fire retardant features. A dedicated material has been developed and is used at present.

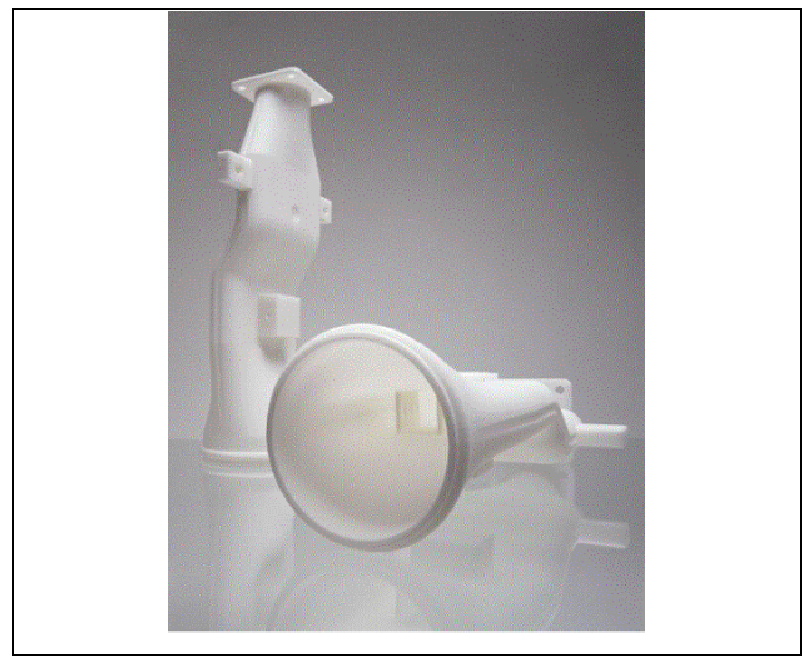

Figure 46. ADM Advanced Digital Manufacturing: direct production of air ducts(Source 3D systems). 


\subsection{Polymers In production tooling}

An industrial tooling manufacturing and production system which amalgamates several mentioned LM advantages was invented by Gale and al. (US patent $6,287,428$ ) [29]. A manufacturing process for pulp moulds was developed. The Integral design [Design for LM (DLM)] based on the UG CAD software utilizes SLS technology to incorporate the tool body, back-up, support structure and screen as one system (Figure 47). The polymer screen has no negative reactions with the acids found in paper pulp from inks, adhesives, etc. The relative low forces and temperature loads allows a long life economic tooling system. The SLS process is an excellent and unique manufacturing method for such complex perforated forms.
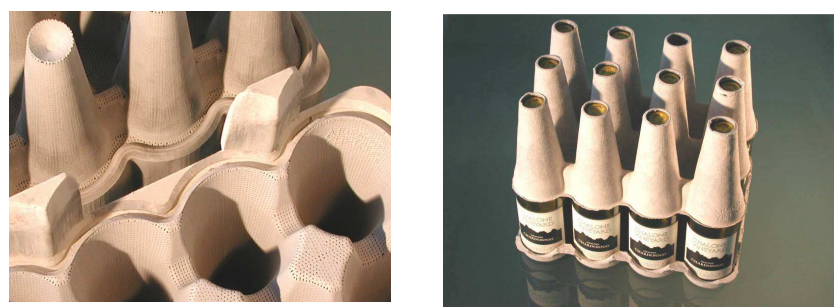

Figure 47. SLS made perforated mould detail for fibre forming (left) and an innovative paper pulp made package for wine bottles (right) (Source: Regale Corp.).

\section{$9 \quad$ MAIN FUTURE ISSUES}

This paper has tried to structure and recapitulate the main moves forwards in the field of rapid manufacturing (RM) or layered manufacturing (LM). The many manufacturing opportunities offered by LM technologies create attractive new possibilities, but are not - by any means - a substitute for established manufacturing processes. The competitive advantages of LM are: geometrical freedom and material flexibility (as far as developed).

The main issues that deserve attention in the near future are:

Materials: Even though LM can already be used to process a wide range of materials (see Figure 3 ), a lot remains to be done to develop better base materials (powders, liquid photopolymers, etc.) that would allow the production of parts with equal strength and other material properties (e.g. thermal, chemical) than those obtained in traditional manufacturing. One may expect cases in the future where LM parts may surpass the properties yielded by traditional manufacturing as a result of LM's unique possibilities to process composite and powder metallurgical materials. For example., powder based processes (see Figure 3) might favour an enlarged use of PM parts (compared to the shift from cast HSS to PM-HSS tools for metal cutting), while many other LM processes might lead to an increased use of metal, ceramic or fibre reinforced plastics or other composite materials (e.g. cermets, MMC). It is expected that research in the coming years will still focus mainly on metals and plastics, but may gradually shift to ceramics and composites.

Design for LM (DLM): In order to take full advantage of LM technologies, one should reconsider the way of designing parts to profit fully from the novel additional design freedom offered by those processes. LM may offer unique possibilities to produce light weight or low inertia parts (e.g. production of porous components by SLS), functional gradient materials (e.g. with CBM or LENS), complex geometries (all LM processes), micro parts (e.g. by micro SLA or SLM), etc. This design freedom might offer unique opportunities in applications like customised production (see example of hearing aids above), medical application, aerospace parts (e.g. light weight), MEMS, etc. These issues might call for research and development in the area of dedicated CAD design software incorporating design for LM modules.

From near to net-shape: Accuracy is still a major limiting factor of present day LM processes. Existing processes and process chains have to go through extensive improvements towards a reliable and secure production technology that match the state of the art in terms of quality and accuracy. All mentioned processes have similar performances in accuracy (0.1-0.2 mm / $100 \mathrm{~mm}$ ), surface finish (Ra 5-20 $\mu \mathrm{m})$ and low repeatability. The efforts for improvement have to start with machine design, through technological feedback systems, over technological optimisation. The combination with traditional processes in multiprocessing equipment might be explored, in particular in combinations using HSC and PKM.

Economics: The productivity is an issue that was partially improved in 3DP for instance. However, even though the processing speed of several LM processes has already improved by more than a factor of ten [58], at lot of effort is still required to further boost production rate. Moreover, the situation in the market place, due to the great divergence of machines offered and their costs, leads to exaggerated equipment and material cost. This creates a non-realistic competitive situation and hinders a broader use of those technologies.

Consolidation: Despite a large number of patents, research results and success claims, a real break through did not happen. The opportunities are there, but one may wonder what is causing the success delay? What are the reasons for the hesitating break through? Will selective laser melting, for instance, have a quicker or immediate success? In future, application dedicated equipment will probably replace the all-round systems.

\section{CONCLUSIONS}

In recent years, one has observed a move from Rapid Prototyping (RP), to Rapid Tooling (RT), to an embryo of Rapid Manufacturing (RM). Layer Manufacturing (LM) definitely offers interesting future potential in this latter aspect. The authors believe that three major application areas may be recognised (Figure 48). A small number of major 
industrial players will probably dominate the LM market, even though numerous additional small ventures will try to penetrate the market of LM equipment and hardware or software accessories.

A possible scenario is given in Figure 48:

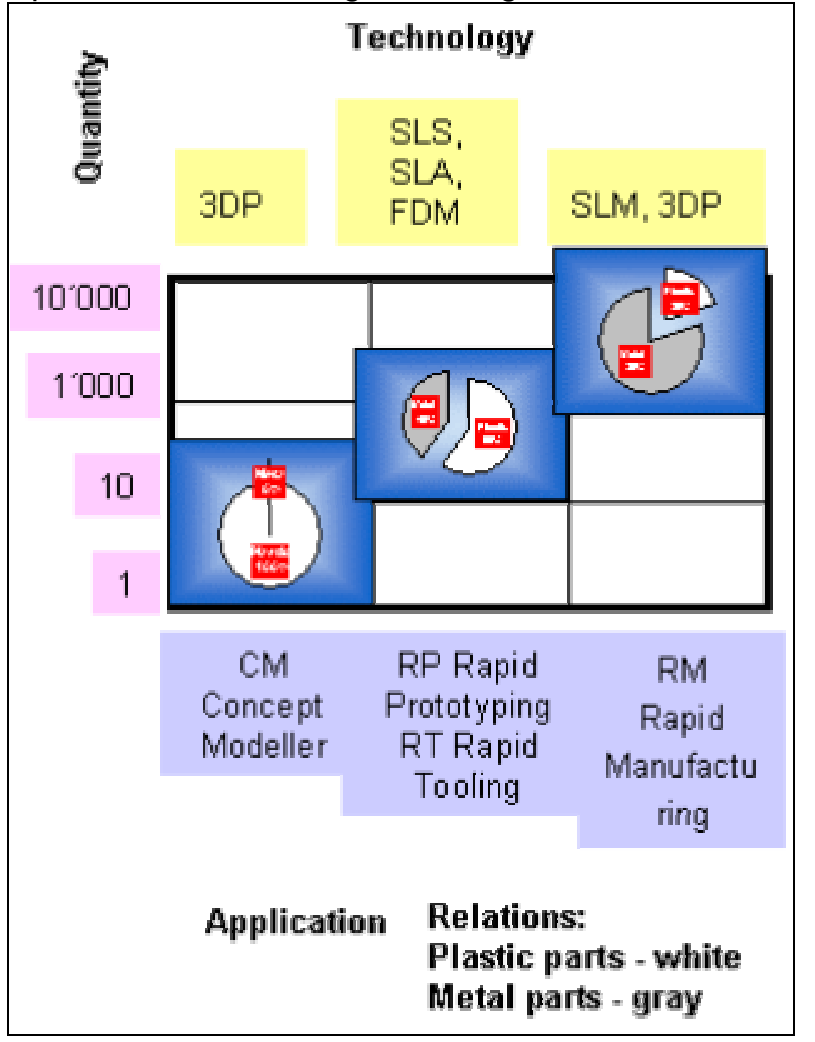

Figure 48: Consolidation forecast for the LM technologies $2002-2010$.

Distinction is made between:

- Concept Modellers (CM): office equipment, close to CAD peripherals, mainly based on 3D Printing technology (e.g. Objet Quadra) for production of visual 3D models for design verification. Material: low grade, but easily processable plastics (wax, photo-curing resins). Production quantity: 1 to 20 . Rapid Prototyping (RP) and Rapid Tooling (RT) equipment: for production of functional prototypes and null-series for tests and small lots. Parts produced directly in metal or higher grade plastics, supported by complementary secondary technologies like RTV (room temperature vulcanisation), investment casting, etc. Production quantity: 10 to 500 . Technologies: SLS, SLA, FDM.

Rapid Manufacturing (RM) equipment: for near net shape production of serial parts and full functional parts. Production quantity: over 500 to several thousands. Technologies: SLM; 3DP.

It is a fact that rapid prototyping has gained a very wide acceptance over the last decade, with an estimated production of 3.55 million models and prototypes in 2001 and a steady growth of about $20 \% / y e a r$, a sales of 1000-1500 machines/year over the last 5 years and about $400 \mathrm{RP}$ service bureaus world wide offering RP services. The market of rapid tooling (i.e. the first application of rapid manufacturing for direct and fast production of tools) is still much more limited, but has nevertheless found numerous real applications for the production of soft tools (for limited series) and hard tools (e.g. SLS tools for series up to 100.000 shots). As for real direct rapid manufacturing of products, its application is still in its infancy, even though very promising. The real breakthrough of RM will mainly depend on cost and productivity improvements, which have to be accompanied with further technical progress in material properties and most of all in accuracy and reliability.

\section{ACKNOWLEDGMENTS}

This paper was already published in Annals of the CIRP, Vol. 52/2, 2003, 589-609 (holding the copyright).

The authors would like to thank colleague, institutes, companies and friends for their contributions and valuable information, papers and remarks (in alphabetical order):

Bernard A., Baus A., Childs T.H., Dickens Ph., Eßer G., Geige M, Gibson I., Glardon R., Himmer T., Klocke F., Kovalenko V., Kunieda M., Leu M., Meiners W., Otto A., Over C., Shellabear M., Nakagaw T., Poprawe R., Resnick R., Schumacher M.B., Wissenbach K.

\section{REFERENCES BY NAME}

[1] Abe F. Osakada K., 1996; Fundamental Study of Laser Rapid Prototyping of Metallic Parts; Int. J. Japan Soc. Pre. Eng.; Vol 30, No 3; 278 $-279$

[2] Abe F. Osakada K., Shiomi M., Uematstu K., Matsumoto M.; 1999; Manufacturing of Hard Tools From Metallic Powders by Selective Laser Melting; Proc. Of AFDM 99, Haeundae, Pusan, Korea September 7-9, 1999 ; 721 - 726

[3] Abe F. Osakada K., Shomi M., Uematstu K., Matsumoto M.; 1999; Direct Manufacturing of Metallic Tools by Laser Rapid prototyping; Advanced Technology of Plasticity, Proc. Of the 6th ICTP, September 19-24; Vol. 2; 10051010

[4] Abe F., Yoshidome A., Osakada K. ,Matsumoto M, ; 2000; Manufacturing of Titanium Parts for Medical Purposes by Selective Laser Melting; Proc. 8th Int. Conference on Rapid Prototyping. June 12-13, 2000, Tokyo, Japan; 288 - 293

[5] Abe F., Yoshidome A., Osakada K., Shiomi M.; 1998; Direct Manufacturing of Metallic Model by Laser Rapid prototyping; Int. J. Japan Soc. Pre. Eng.; Vol 32, No 3; 221-222

[6] Altan T. , Lilly B.,Yen Y.C. ; 2001; Manufacturing of Dies and Moulds ; CIRP Annals; Vol 50/1; 405-409

[7] Anderson, R.; Lembo, J.; Rynerson, M.;; 2002; Rapid Manufacturing of Metal Matrix Composite Materials Using Three-Dimensional Printing (3DPTM). ; Proceedings of TMS International Fall Conference ; 2002, in press

[8] Andersson L. E., Larsson M; 2001; Device and Arrangement for Producing a Three 
Dimensional Object; Pat: PCT WO 01/81031 A1 Priority 27.4.2000

[9] Arthur A., Hwee O. K.; 2000; The Feasibility of Rapid Prototyping Forging Dies; Proceedings of the 9th European Conference on Rapid Prototyping and Manufacturing July 2000, Athens, Greece ; 163172

[10] Bakkelund J. , R. Karlsen, OE. Björke (1); 1997; Fabricating metal objects using layer manufacturing technology and powder metallurgy science; Annals of the CIRP; Vol 46/1/1997; 135-138

[11] Bampton; C.C., Burkett; R.,; Hong S., ; 1996; Free Form fabrication of metallic components ; Pat. US5,745,834;

[12] Beaman Joseph J., Barlow Joel W. , Bourell David L. Crawford Richard H., Marcus Harris L., McAlea Kevin P.; 1997; Solid Freeform Fabrication: A new Direction in Manufacturing; Kluwer Academic Publishers; ;

[13] Bernard A.,..Fischer A.; 2002; New Trends in Rapid Product Development; CIRP Annals; Vol $51 / 1 / 2002$

[14] Bertch A., Bernhard P., Vogt Ch., Renaud Ph.; 2000; Rapid prototyping of small size objects; Rapid Prototyping Journal; vol.6; 259 - 266

[15] Berzins M. , T.H.C. Childs, G.R. Ryder; 1996; The selective laser sintering of polycarbonate; Annals of the CIRP; Vol 45/1/1996; 187-190

[16] Boillat E., Kolosov S., Glardon R., Loher M., Levy G. ; 2002; Finite Element and Neural Network Models for Process Optimisation in Selective Laser Sintering; Proceedings of the ICME 2002, July 2002, Ischia Italy, ISBN - 8887030-44-8; pp 375 - 380

[17] Bourell d.L., Marcus H.L.,Barlow J. W.,Beaman J. J.,Deckard C. R.; 1994; Multiple material systems for selective beam sintering ; Patent US 5,382,208 filled 21.5.1994;

[18] Campbell R.I., Martorelli M.; 2000; Surface Roughness Performance of Rapid Prototyping Processes - a Comparative Analysis; Proceedings of the 9th European Conference on Rapid Prototyping and Manufacturing July 2000, Athens, Greece ; 37-44

[19] Childs T:H: Tontowi; 2001; Selective laser sintering of a crystalline and a glass-filled crystalline polymer: experiments and simulations; Proceedings of the Institution of Mechanical Engineering, Journal of Engineering Manufacture; Vol 215 B11 ISSN 0954-4054; pp 1481-1495

[20] Chishti M., Pham L.X.; 1999; System and Method for Releasing Tooth Positioning Appliances; Patent US 6,183,248 Priority 16.2.1999 con. US 6,390,812 prio 8.1.2001

[21] Christman A., J. Naysmith,; 2000; Mould making Operations \& Requirements MultiClient research Study; www.CIMdata.com;

[22] Crawford R.H., Beaman J. J.,Bourell D.L., Wood K.L.; 2001; Advances in Multiple Material Solid Freeform Fabrication; Proceedings of the SME RPA conf., 15-17 May 2002 Cincinnati USA

[23] Dalgarno K.W. Stewart T.D.; 2001; Manufacture of production injection mould tooling incorporating conformal cooling channels via indirect selective laser sintering ; Proc Instn Mech Engrs; Journal Manufacture Vol215 Part B; 1323-1332

[24] Dickens Ph., Ruggley M., 2001, Direct AIM ${ }^{T M}$ in a new direction, SME Conference Rapid Prototyping \& Manufacturing 14-17 May 2001, Cincinnati $(\mathrm{OH})$

[25] Dutta D., Shiptalni M.; 2000; Heterogeneous solid modelling for layered manufacturing; CIRP Annals; 49/1/2000; 109

[26] Esser G, Niebling F., Geiger M.; 2001; Rapid Tooling - Current Status and Future Trends; Proceedings of the $\mathrm{ICl}$ conference ;

[27] Fährer Jörg; 2002; Ganzheitliche Optimierung des indirekten Metal-Lasersinter-prozesses; B163 Herbert Utz Verlag; Diss. Iwb; ISBN 38316-0124-0

[28] Freyer C., Klocke F.; 2001; Fast Manufacture of High Strength Tools from Steel using CMB; SME Conference Rapid Prototyping \& Manufacturing 14-17 May 2001, Cincinnati $(\mathrm{OH})$

[29] Gale G. W.,Haugen J. J.; 1999; Mould with integral screen and method for making mould and apparatus and method for using the mould ; Patent US 6,287,428 Prio 30.8.1999;

[30] Gatto A., Iuliano L., Ippolito R.; 2000; Micro Joining Mechanisms Between Metal Partials in the SLS Process; Proceedings of the 9th European Conference on Rapid Prototyping and Manufacturing July 2000, Athens, Greece ; $23-36$

[31] Gibson I., Cheung W.L., Ling W.M., Ting F.P.Y., Ho H.C.H.,; 2000; SLS Multiple Material Systems; Int. Journal of CAD/CAM and Computer Graphics, vol. 15, nos. 2-4, 2000, ISSN 0298-0924, ; pp165-176

[32] Gibson I., W.L. Cheung, F.P.Y. Ting, W.M. Ling, H.C.H. Ho, J.C.W. Ku; 2002; Multiple Material Polymer Systems based on the Selective Laser Sintering Process; Proc. Int. Conf. on Rapid Prototyping and Manufacturing, Beijing, August 2002

[33] Glardon R., Boillat E., Paraschivescu D.; 2003; Thermal Optimisation of Injection Moulds Produced by Layered Manufacturing Techniques ; to be published;

[34] Glardon R., Karapatis N., Romano V.; 2001; Influence of $\mathrm{Nd}$ :YAG Parameters on the Selective Laser Sintering of Metallic Powders; CIRP Annals; 50/1/2001; 133-136

[35] Goetzen R., Reinhardt A.; 2000; Rapid Micro Product Development RPDM® Schlüsseltechnologie für die Aufbau- und Verbindungstechnik von Mikrosystemen; Company publication;

[36] Griffith M. L. M., Ensz T., Puskar J.D.,Robino C.V., Brooks J.A., Philliber J.A., Smugeresky J.E., Hofmeister W.H.; 2000; Understanding the Microstructure and Properties of Components Fabricated by Laser Engineered Net Shaping (LENS®), ; Proceedings Materials Research Society Symposium Proceedings, April 2000 ; V625;

[37] Gu P. Li L.; 2002; Fabrication of Biomedical Prototypes with Locally Controlled Properties 
Using FDM; CIRP ANNALS 2002 Vol.51/1/2002 pp 181 - 184

[38] Hans Jäger, Gideon Levy, Ralf Schindel; 2001; New Technologies to Shorten Time to Market: The Impact of Actual and Future Rapid Prototyping Technologies ; Proceedings of IE\&EM '2001, Tianjin. China

[39] Herzog F.; 2002; LaserCUSING, Bindeglied für Rapid Tooling u. trad. Werkzeugbau; Proceedings of the SWISS Rapid Forum 02, 20.6.02; B 5,2

[40] Herzog F., Herzog K.; 2002; Device for Sintering, Removing Material and/or Labelling by Means of Electro magnetically Bundled Radiation and methods for Operating the Device; Patent WO 02/36331 A2 Priority 30.10.2001

[41] Hessel H.E.; 2002; NemoTech ${ }^{\mathrm{TM}}$; Proceedings of the SWISS Rapid Forum 02, 20.6.02; B 6,1

[42] Hickmann Th.; 2002; Problems and possible solutions for the production of plastic, rubber and silicone parts with rapid tooling moulds; Proceedings of the Euro uRapid 2002, December 2002, Frankfurt

[43] Himmer T., Techel A. Nowotny S., Beyer E.; 2002; Recent Development in Metal Laminated Tooling by Multiple Laser Processing ; Proc. EURO-uRapid, 2-3.12.2002, Frankfurt, Germany

[44] Hull Ch., Newell K., 2002, Recoating system for using high viscosity build materials in solid freeform fabrication, US Patent Appl. 20020195747.

[45] Ippolito R., luliano L., Gatto A.; 1995; Benchmarking of rapid prototyping techniques in terms of dimensional accuracy and surface finish; CIRP Annals; 44/1/1995; 157

[46] Johnston, S. and Anderson, R; 2002; Finite Element Thermal Analysis of Three Dimensionally Printed (3DPTM) Metal Matrix Composites; Proceedings of Solid Freeform Fabrication Symposium 2002; 2002, in press

[47] Karpatis N., Glardon R.; 1998; Recours au procédé SLS pour le Rapid Tooling; Proceedings of the WZMO Conference, ETHZ

[48] Karpatis N., Gygax P.E. Glardon R.; 1998; Thermal Behaviour of Parts made by Direct Metal Laser Sintering; Proceedings of the 8th Solid Freeform Fabrication Symposium Austin (USA

[49] Karpatis N., Van Greithuysen J.P., Glardon R.; 1998; Direct Rapid Tooling: a Review of Current Research; Rapid Prototyping Journal;

[50] Karpatis N., Van Griethuyse J.P., Glardon R., ; 1997; Injection Moulds Behaviour and Lifetime Characterization: Concept ; Proceedings of the 7th Solid Freeform Fabrication Symposium Austin (USA

[51] Katz Z. Smith P.E.S.; 2001; On process modelling for selective laser sintering of stainless steel; Proceedings of the Institution of Mechanical Engineering, Journal of Engineering Manufacture; Vol 215 B11 ISSN 0954-4054; pp 1497 - 1504

[52] Khaing M.W., Fuh J.Y.H., Lu L., ; 2001; Direct metal laser sintering for rapid tooling: processing and characterisation of EOS parts;
Journal of Materials Processing Technology; 113(2001); 269-272

[53] Kloke F. Wirtz H.; 1998; Selective Laser Sintering of Zirconium Silicate; Proceedings of the 7th European Conference on Rapid Prototyping and Manufacturing July 1998 Aachen, Germany ; 307-314

[54] Koch J., Mazumder J., 2000, Apparatus and Method for Monitoring Multi Layer Laser Cladding, US Patent 6,122,564 prio. 30.6.1998.

[55] Krause F. L., M. Ciesla, Ch. Stiel, A. Ulbrich; 1997; Enhanced rapid prototyping for faster product development processes; Annals of the CIRP; $1 ; 93$

[56] Kruth J. P.; 1991; Material Incress Manufacturing by Rapid Prototyping Techniques; CIRP Annals 1991; 40/2/1991; 603-614

[57] Kruth J.P.; 1994; Advances in physical and chemical machining, keynote paper; Advancement of Intelligent Production, (E. Usui, ed.), JSPE Publication Series $n^{\circ} 1$, Elsevier Science B.V., ISBN 044481901 0, pp. K62-K76

[58] Kruth J.P. , B. Van der Schueren, J.E. Bonse, B. Morren; 1996; Basic powder metallurgical aspects in selective metal powder sintering; Annals of the CIRP; 45/1/1996; 183-186

[59] Kruth J.P., et.al.; 1998; Progress in Additive Manufacturing and Rapid Prototyping; CIRP Annals 1998; 47/2/1998; 525-532

[60] Kruth J.P., et.al.; 2001; Lasers and Materials in Selective Laser Sintering; Keynote paper, Proc. $3^{\text {rd }}$ Laser Assisted Near-shape Eng. Conf. (LANE 2001), Erlangen, Germany; ISBN 387525-154-7; 45352

[61] Kruth J.P., Van der Schueren B.; 1997; Soft and hard tools for polymers and metal casting/moulding; Proc. Colloquium "Werkzeugbau", EMO Hanover; 175-194

[62] Lanzetta M., Sachs E.; 2001; Optimisation of the Quality with Dry Powders in Three Dimensional Printing; Proceedings of PRIME 2001, CIRP Seminar, 20-22 June 2001 Sestri Levante, Italy Genoa, Italy; ISBN 88-900559-0$1 ; 197-204$

[63] Lanzetta M., Sachs E.; 2001; The Line Formation with Alumina Powders in Drop on Drop Demand Three Dimensional Printing; Proceedings of PRIME 2001, CIRP Seminar, 20-22 June 2001 Sestri Levante, Italy Genoa, Italy; ISBN 88-900559-0-1; 189-196

[64] Laoui T., Froyen L., Kruth J.P.; 1998; Effect of mechanical alloying on selective laser sintering of WC-9Co hard metal powder; Proc. Powder Metallurgy World Congress, Spain, 18-22 Oct., 394-399.

[65] Laoui T., Froyen L., Kruth J.P.; 1999; Alternative binders to Co for WC particles for SLS process; Proc. 8th European Conf. on Rapid Prototyping and Manufacturing, Nottingham, 6-8 July, 299-311.

[66] Laoui T., Froyen L., Kruth J.P.; 2000; Effect of mechanical alloying on selective laser sintering of WC-9Co powder, Powder Metallurgy, Vol. 42(3), 203-205 
[67] Lembo, J. and Anderson, R; 2002; Rapid Solid Freeform Manufacturing Using Three Dimensional Printing (3DPTM); Proceedings of ASNE Manufacturing Technology for Ship Construction and Repair Symposium 2002; 2002, in press

[68] Levy G. , Ralf Schindel, Wahyo Nursanto; 2001; Selektives Lasersintern - Neue Chancen im Produktions-Entwicklungsprozess; Ostschweizer Technologiesymposium 2001, St. Gallen

[69] Levy G. , Scherrer J., Schindel R.; 2000; Layer Manufacturing a powerful complementary technology in RPD (rapid product development cycle); 2000 International CIRP Design Seminar, May Haifa

[70] Levy G. , Schindel R. , Nursanto W.; 2001; Rapid Product Development applying SLS (Selective Laser Sintering) Rapid Tooling with Interactive Modelling and Simulations; Proceedings of PRIME 2001, CIRP Seminar, 20-22 June 2001 Sestri Levante, Italy Genoa, Italy

[71] Levy G. , Schumacher B., Schindel R. , Nursanto W.; 2001; Rapid Tooling Technologies enabling the integration of product design and Production; ISEM XIII 2001; ;

[72] Levy G.N.; 1997; Systematische

Werkstoffentwicklung erweitert den Nutzen beim Einsatz von Selektive LASERsintern SLS; Proceedings WZMO Lausanne October 1997

[73] Levy G.N.; 2000; Layer Manufacturing a powerful complementary technology in RPD (rapid product development cycle); The International Journal foe Manufacturing Science \& Production; Vol 3 ISSN 0793-6648; 159-166

[74] Levy Gideon, J. Scherrer, R. Schindel, Bernd Schumacher; 1999; Verfahrensgerechte Werkstoffe und praxisnahe Prozessketten für das Lasersintern, ; VDI-Zeitschrift Integrierte Produktion; Nov. 1999, ; pp 28-30

[75] Levy N. G., Schindel R., ; 2003; Overview of Layer Manufacturing Technologies, Opportunities, Options and Applications for Rapid Tooling; Proc Instn Mech Engrs; Journal Manufacture; Vol 216 Part B; 1621-1634

[76] Levy N. G., Schindel R., Schleiss P.; 2002; Understanding SLS Metal LaserForm ST-100; Proceedings SLS Users Group, 29 September - 3. October 2002, San-Francisco

[77] Levy N. G. Schumacher M. B., 2003, Rapid Prototyping of EPS (expandable polystyrene) for Lost Foam castings, $36^{\text {th }}$ CIRP International Seminar on Manufacturing, 03-05 June 2003, Saarbrücken, Germany

[78] Lonardo P.M. , Lucca D.A., De Chiffre L.,; 2002; Emerging Trends in Surface Metrology; CIRP Annals ; Vol 51/2/2002; 701- 723

[79] Macht Michael; 1999; Ein Vorgehensmodell für den Einsatz von Rapid Prototyping; B131 Herbert Utz Verlag; Diss. Iwb; ISBN 3-89675638-9

[80] Master M., Mathey M., ; 2002; Direct Manufacturing of Custom-made Hearing Instruments an implementation on Digital
Mechanical Processing; Proceedings of the SME RPA conf., 30 April - 2, May 2002 Cincinnati USA

[81] Masuzawa T.; 2000; State of the art of Micromachinig; Annals of the CIRP; 49/2/2000; 473-488

[82] Meiners W., Over C., Wissenbach, K., Poprawe R; 1999; Direct generation of metal parts and tools by Selective Laser Powder Re melting (SLPR), ; Proceedings of the Solid Freeform Fabrication Symposium, Austin Texas 1999

[83] Meiners W.; Wissenbach K., Gasser A, ; 1996; Selective laser sintering at melting temperature ; Pat. US 6,215,093.

[84] Meiners, W.; 1998; Direktes Selektives Laser Sintern einkomponentiger metallischer Werkstoffe; Dissertation RWTH Aachen;

[85] Meyer E. B.; 1998; Herstellung komplexer Präzisionsteile in grossen Serien Pulvermetallurgisch gespritzt ; Swiss Maschine Market; Vol 47/ 1998; Pp72 - 74.

[86] Micari F. Fratini L., Levy G.; 2002; Wear of SLS Rapid Form Metal sheet forming Tool; Internal reports, Univ. Palermo, Uni. Applied Sciences ST. Gallen.

[87] Micari F. Fratini L., Levy G., Schindel R., Schleiss P.; 2003; On the use of SLS Tools in Sheet Metal Stamping;CIRP Annals Vol $52 / 1 / 2003$

[88] Montero M., Roundy S., Odell D., Ahn S.H., Wright P.K.; 2001; Material Characterization of Fused Deposition Modelling (FDM) ABS by Designed Experiments; Proceedings of the SME RPA conf., 15-17 May 2002 Cincinnati USA.

[89] Mueller D.H., Mueller H.; 2000; Experiences Using Rapid Prototyping Techniques to Manufacture Sheet Metal Forming Tools; Proceedings of ISATA 2000, Dublin Ireland, September, 2000.

[90] N. Karapatis,G. Egger, P.-E. Gygax,R. Glardon ; 1999; Optimisation of Powder Layer Density in Selective Laser Sintering; Proceedings of the 9th Solid Freeform Fabrication Symposium, Austin (USA).

[91] N.N; 2002; Das Aufbauen von Werkzeugkernen mit Laserenergie; Der Stahlformbauer; 37408; 28-32.

[92] Nakagawa T.; 1993; Recent Developments in Auto Body Panel Forming Technology; CIRP Annals; 42/2/93; 717-722.

[93] Nakagawa T., Kunieda M.; 1984; Manufacturing of Laminated Deep Drawing Dies by Laser Beam Cutting; Advanced Technology of Plasticity; vol 1.

[94] NN; 2002; SME published glossary ; http://www.sme.org/cgi-

bin/getgmnpage.pl?/rpa/glossary.htm\&\&\&RPA \&.

[95] Nöken Stefan; 1997; Technologie des Selektiven Lasersinterns von Thermoplasten; Shaker Verlag, 1/168 Band 8/97; Diss. RWTH Aachen.

[96] Nyrhila Olli Juhani, .Ang.bo, ; 1994; Method for fabricating dimensionally accurate pieces by laser sintering ; Pat US 5,732,323; 
[97] Osakada K. , Abe F.; 1999; A Study of Laser Prototyping for Direct Manufacturing of Dies from Metallic Powders; 923 - 926

[98] Over C., Meiners W., Wissenbac K., Lindemann M., Hutfless J.; 2002; Selective Laser Melting a New Approach for the Direct Manufacturing of Metal Parts and Tools; Proceedings of SME conference on Rapid Prototyping and Manufacturing, Cincinnati 2002; May 2002

[99] Pham D.T., Dimov S.S.; 2001; Rapid Manufacturing, The Technologies and Applications of Rapid Prototyping and Rapid Tooling; Springer-Verlag; 1/214 ISBN 1-85233360-X

[100] Pham D.T., Wang X.; 2000; Prediction and reduction of build times for the selective laser sintering process; Proceedings of the Institution of Mechanical Engineering, Journal of Engineering Manufacture; Vol. 214; 425-430

[101] Phol H., Gosger P.; 2001; Three dimensional printing Prometal A New Technology for the Fabrication of Tools; Proceedings of the uRapid 2001, May 2001, Amsterdam, Netherlands; 248-252

[102] Prinz F.B.; 1997; Building parts you could not build before; Rapid Product Development; Proc. $8^{\text {th }}$ Int. Conf. On Prod. Eng. (ICPE-8), Chapman \& Hall, ISBN0412\&1160X, 40-48

[103] Rabinovich J.E.; 2002; Laser precision Metal deposition PMDTM ; Proceedings of the SME RPA conf., 30 April - 2, May 2002 Cincinnati USA

[104] Rabinovich J.E.; 2002; Rapid Manufacturing System for Metal Matrix Composite Materials and Ceramics; Patent US 6,459,069 B1 Priority 29.10.2000

[105] Rosochowski A., Matuszak A.; 2000; Rapid Tooling: the state of the art; Journal of Materials Processing Technology; 106(2000); 191-198

[106] Rudgley M.; 2001; Rapid manufacturing - the revolution is beginning; Proceedings of the uRapid 2001, May 2001, Amsterdam, Netherlands; 441-444

[107] Sachs E., Cima M.,Cornie J.,Suh N.P. (1); 1990; Three dimensional printing: rapid tooling and prototypes directly from a CAD model; CIRP Annals; 39/1/1990; 201

[108] Safari A., Danforth S.C., Jafari M., Allahverdi M., Jadidan B., Mohammadi F., Rangarajan S.; 2000; Fabrication of Advanced Functional Ceramics by Fused Deposition Technique ; Proceedings of the 9th European Conference on Rapid Prototyping and Manufacturing July 2000, Athens, Greece

[109] Schindel, R. et. al.; 2002; LaserForm Formeinsätze; Proceedings of the SWISS Rapid Forum 02, 20.6.02

[110] Schumacher B., Levy N.G.; 1998; Selective Laser Sintering Combined with Systematic Development of New Powders Enabling Innovative and Prosperous Redesign of Process-Layouts; Proceedings of the 12th ISEM 11-13.5.1998, Aachen Germany; 324 331
[111] Sercombe T.B., Schaffer G.B., Calvert P.,; 1999; Freeform fabrication of functional prototypes using powder metallurgy; Journal of Materials Science; 34; 4245-4251

[112] Sercombe T.B., 2002; Selective Laser Sintering of Merging Steel", ; Submitted to Materials Science and Engineering April 2002

[113] Sercombe T.B., Schaffer G.B.; 2002; Development of Infiltrated Aluminium Components via Selective Laser Sintering; Proceedings SLS Users Group, 29 September - 3. October 2002, San-Francisco

[114] Shellabear M.; 2002; Direct Metal LaserSintering (DMLS) with 20 microns layers: Proceedings of SME conference on Rapid Prototyping and Manufacturing, Cincinnati 2002; May 2002

[115] Shellabear M., Danzig A., Heugel M., Kotila J., Nyrhilä O. ; 2001; The Breakthrough to 20 micron layers increasing precision and efficiency in Direct Metal Laser-Sintering; Proceedings of the uRapid 2001, May 2001, Amsterdam, Netherlands; 256-267.

[116] Shiomi M.,Yoshidome A., Abe F., Osakada K.,; 1999; Finite Elements Analysis of Melting and Solidifying Processes in Laser Rapid Prototyping of metallic Powders ; Int. Journal of Machine Tools \& Manufacture; Vol 39; 237 252.

[117] Song Y.A., W. König ; 1997; Experimental study of the basic process mechanism for direct selective laser sintering of low-melting metallic powder; Annals of the CIRP; 46/1/1997; 127-130.

[118] Song Yong-Ak; 1996; Selektives Lasersintern metallischer Prototypen; Shaker Verlag, 1/116 Band 2/96; Diss.RWTH Achen.

[119] Spielman R.; 2002; From Aerospace Back Home: Rapid Manufacturing in the Private Sector; Proceedings SLS Users Group, 29 September - 3. October 2002, San-Francisco.

[120] Stewart T.D., Dalgarno K.W., Childs T.H.C.; 1999; Strength of the DTM Rapid Steel 1.0 material; Materials and Design; 20(1999); 133138.

[121] Stucker; B. E.,Walter L.; Philip T., Bozkurt; B.; 1997; Manufacture and use of $\mathrm{ZrB2} / \mathrm{CU}$ composite electrodes ; Pat. US 5,870,663.

[122] Syrjala S.; 2002; Rapid Tooling and Manufacturing: Last Case studies in Finland; Proceedings of SME conference on Rapid Prototyping and Manufacturing, Cincinnati 2002; May 2002.

[123] Thierry Dormal; 2000; Etude comparative des techniques actuelles de Rapid Tooling; 8th European Conference on Rapid Prototyping, Paris 3-4, May 2000.

[124] Van der Schueren B.; 1996; Basic contributions to the development of the Selective Metal powder Sintering process; PhD thesis, K.U.Leuven, Belgium.

[125] Vasinonta A., Beuth J.L., Griffith M.L.; 2000; Process Maps for Controlling Residual Stress and Melt Pool Size in Laser-based SFF Processes; Proceedings of the Solid Freeform Fabrication Symposium, August, 2000, Austin, TX. 
[126] Wang X., Kruth J.P.; 2000; A simulation model for direct selective laser sintering of metal powders; Computational Techniques for Materials, Composites and Composite Structures, Civil-Comp Press, Edinburgh, 5157.

[127] Wang X.C., Kruth J.P.; 2001; Finite Element Analysis of Thermal Process in Direct Selective Laser Sintering; Proceedings of PRIME 2001, CIRP Seminar, 20-22 June 2001Sestri Levante, Italy Genoa, Italy; ISBN 88-900559-01; 205-210.

[128] Wheelwright S.C., Clark K.B; 1992; Revolutionizing Product Development; The Free Press - Macmillan, Inc; ISBN 0-02905515-6.

[129] White D., ; 2002; Ultrasonic Consolidation: Direct to Metal Cores-Cavities; Proceedings of SME conference on Rapid Prototyping and Manufacturing, Cincinnati 2002; May 2002.

[130] Wohlers Terry T.; 2001; Rapid Prototyping \& Tooling, State of the Industry, Annual Worldwide Progress Report; Wohlers Associates; twohlers@compuserve.com.

[131] Xue, L.,.2001, Free-Form Laser Consolidation \& Its Potential Applications for Mould Making. Invited presentation for the Mould Makers Council of the Canadian Plastics Industry Association. 25, January 2001

\section{BIOGRAPHY}

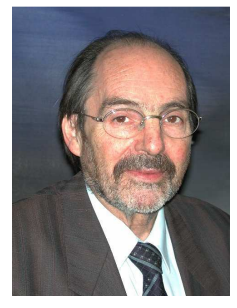

Prof. Dr. Gideon N. Levy Studied at IIT (Technion Israel Institute of Technology Haifa) B.Sc. (1966): Mechanical Engineering (cum lauda), M.Sc. (1968): Control Engineering, D.Sc.

Manufacturing Technology

1973-1989 AGIE AG for Industrial Electronic, Switzerland; EDM (Electro Discharge Machining) Technologies, Product management. Head f R\&D AGIE.

1989-1995 Soudronic AG Switzerland, CTO Vice President; Welding Technologies, Technology Management

1996 TTA Technology Turn Around; Industrial Consulting, Start-Up companies consulting

1997 Head of Mechatronic department, and Head of the Centre for Reverse Engineering and Rapid Prototyping at the University of Applied Sciences St. Gallen, Switzerland.

2001 Head of Institute for Rapid Product Development (RPD) University of Applied Sciences St. Gallen, Switzerland
Prof. Levy's career has been mainly in advanced $R \& D$ in Mechanical / Electronic manufacturing systems in the machinery industries. Specialising in Manufacturing technologies, Technology management, Market - Product strategies, key customers, industrial scientific and technical aspects of product design and manufacture, market launch and technology transfer. Lately focusing on freeform fabrication, reverse engineering simulations and Rapid Product development techniques. A wide range of academic activities have been kept up ( MTDR, ISEM, SME, CIRP, etc.) human resource management and education are ongoing activities.

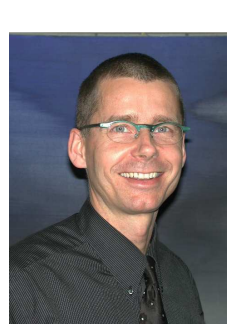

Ralf Schindel, born :09.05.1965, Nationality : Swiss

\section{EDUCATION}

1990 B.Sc. in Mechanical Engineering.

1993 MBA Business

Administration and Ecology

\section{ACTIVITIES}

1991 - 1992 Mechanical design and simulation in the aeronautics

1993 - 1994 Product management in ecological engineering recycling systems

1995 - 1996 Establishing an Educational Center for Die and Tool Making in Malaysia

1996 - University of Applied Sciences St. Gallen, Institute for Rapid Product Development , Deputy Head of the Institute,

Research and project manager in freeform fabrication, reverse engineering and medical applications.

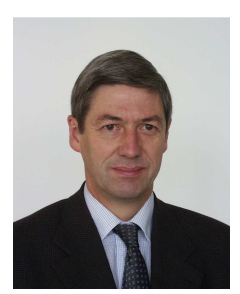

Prof. Dr. Ir. Jean-Pierre KRUTH is full professor at the Catholic University of Leuven (K.U.Leuven, Belgium), where he is responsible for Production Engineering research and education at the division PMA of the Department of Mechanical Engineering (Recipient of the 1998 CASA/SME University LEAD Award). His activities involves: CAD, CAPP, CAM, production processes, metal cutting, non-traditional machining, rapid prototyping, dimensional metrology, quality control, reverse engineering.

He obtained his Ph.D. at K.U.Leuven in 1979 and worked at the Institut Technologi Bandung (ITB, Indonesia) from 1979 till 1982. He was research engineer at the Scientific and Technical Center of the Belgian Metalworking Industry (CRIF/WTCM) and half-time consulting engineer at the national 'Stand-by CAD/CAM' service for industry (IWONL), till being nominate full-time at K.U.Leuven in 1987.

$\mathrm{He}$ is Active Member of CIRP, Fellow of SME, Honorary member Romanian Society of Mech. Eng., 
Member of Belgian Royal Academy Council of Applied Sciences, Board Member BSMEE (Belgian Soc. Mech. \& Envir. Eng.), Member IMEKO/BEMEKO (International/Belgian Measuring Confederation), member K.VIV, founding board member of companies MATERIALISE N.V. (>1997), METRIS N.V. and MIH N.V.

Appendix 1: Commercially available Direct Metal Parts manufacturing systems

A [1] SLS, Powder, 3D systems,http://www.3DSystems.com/,DTM_SLS_SLA- Ceramics

A [2] SLS, Powder, EOS,http://www.eos-gmbh.de/ ,DMLS®

A [3] SLS, Powder, Phenix Systems,http://www.phenix-systems.com ,SLS_Ceramics

A [4] 3DP, Powder, Extrudehone,http://www.extrudehone.com/prometal.html

A [5] LOM, Sheets, Sekisou Kanagata Co. Ltd.,http://www.h3.dion.ne.jp/

A [6] LOM, Sheets, Solidica, http://www.solidica.com/,

A [7] LOM,Sheets,Zimermann,http://www.f-zimmermann.com/fzimmermann.html ,LOM (LMC)

A [8] SLM, Powder, Trumpf (ILT),http://www.ilt.fhg.de/, http://www.trumpf.com/

A [9] SLM, Powder, F\&S , MCP HEK GmbH, http://www.fockeleundschwarze.de/english/fsproductsfsrea.html , http://www.mcp-group.de/download/mcp realizer monitor.pdf

A [10] SLM, Powder, Concept Laser GmbH,http://www.concept-laser.de ,

A [11] SLM, Powder, Arcam AB,http://www.arcam.com/, SBM Beam melting

A [12] SLM, Powder, AeroMet, http://www.aerometcorp.com/ ,LENS®

A [13] SLM Paste /Powder, Optomec, http://www.optomec.com/

A [14] SLM, Powder, POM,http://www.pom.net/,DMDTM (Direct Metal Deposition)

A [15] CMB, Powder / Wire, IPT,http://www.ipt.fhg.de/,

A [16] CMB, Powder, Rhoeders, http://www.roeders.del,

A [17] FDM, Wire, H\&R Technology, PDM ${ }^{\mathrm{TM}}$, http://www.hrtechnology.com/

A [18] Spray, MCP HEK GmbH, http://www.mcp-group.de/download/mcp realizer monitor.pdf, 